\begin{tabular}{|c|c|}
\hline Title & $\begin{array}{l}\text { Prediction of } 1,4 \text { dioxane decomposition during V UV treatment by model simulation taking into account effects of } \\
\text { coexisting inorganic ions }\end{array}$ \\
\hline Author(s) & $\begin{array}{l}\text { Matsushita, Taku; Sugita, W ataru; Ishikawa, Tomoya; Shi, Gang; Nishizawa, Shota; Matsui, Y oshihiko; Shirasaki, } \\
\text { Nobutaka }\end{array}$ \\
\hline Citation & $\begin{array}{l}\text { Water research, 164, } 114918 \\
\text { https://doi.org/10.1016/.watres.2019.114918 }\end{array}$ \\
\hline Issue Date & 2019-11-01 \\
\hline Doc URL & http:/hdl .handle.net/2115/83122 \\
\hline Rights & $\begin{array}{l}\text { () 2019. This manuscript version is made available under the CC-BY-NC-ND } 4.0 \text { license } \\
\text { http://creativecommons.org/icenses/by-nc-nd/4.0/ }\end{array}$ \\
\hline Rights(URL) & http://creativecommons.org/icenses/by-nc-nd/4.0/ \\
\hline Type & article \\
\hline File Information & O_matsushitaWR_2019.pdf \\
\hline
\end{tabular}

Instructions for use 


\title{
Prediction of 1,4-dioxane decomposition during VUV treatment by model simulation taking into account effects of coexisting inorganic ions
}

\author{
Taku Matsushita ${ }^{a *}$, Wataru Sugita $^{b}$, Tomoya Ishikawa ${ }^{b}$, Gang Shi ${ }^{b}$, Shota Nishizawa ${ }^{b}$, \\ Yoshihiko Matsui ${ }^{a}$, and Nobutaka Shirasaki ${ }^{a}$ \\ a Faculty of Engineering Hokkaido University, N13W8, Sapporo 060-8628, Japan \\ b Graduate School of Engineering, Hokkaido University, N13W8, Sapporo 060-8628, Japan \\ *Corresponding author: E-mail addresses: taku-m@eng.hokudai.ac.jp, Tel./fax: +81-11-706-7279
}

\begin{abstract}
1,4-Dioxane is one of the most persistent organic micropollutants and is quite difficult to remove via conventional drinking water treatment consisting of coagulation, sedimentation, and sand filtration. Vacuum ultraviolet (VUV) treatment has recently been found to show promise as a treatment method for 1,4-dioxane removal, but the associated decomposition rate of 1,4-dioxane is known to be very sensitive to water quality characteristics. Some computational models have been proposed to predict the decomposition rate of micropollutants during VUV treatment, but the effects of only bicarbonate and natural organic matter have been considered in the models. In the present study, we attempted to develop a versatile computational model for predicting the behavior of 1,4-dioxane during VUV treatment that took into account the effects of other coexisting inorganic ions commonly found in natural waters. We first conducted 1,4-dioxane decomposition experiments with low-pressure mercury lamps and test waters that had been prepared by adding various inorganic ions to an aqueous phosphate buffer. The apparent decomposition rate of 1,4-dioxane was suppressed when bicarbonate, chloride, and nitrate were added to the test waters. Whereas bicarbonate and chloride directly suppressed the apparent decomposition rate by consuming HO•, nitrate became influential only after being transformed into nitrite by concomitant UV light $(\lambda=254$ $\mathrm{nm})$ irradiation. Cl-related radicals $\left(\mathrm{Cl} \bullet\right.$ and $\left.\mathrm{Cl}_{2}{ }^{-}\right)$did not react with 1,4-dioxane directly. A computational model consisting of 31 ordinary differential equations with respect to time that had been translated from 84 reactions (10 photochemical and 74 chemical reactions) among 31 chemical species was then developed for predicting the behavior of 1,4-dioxane during VUV treatment. Nine of the parameters in the ordinary differential equations were determined by least squares fitting to an experimental dataset that included different concentrations of bicarbonate, chloride, nitrate, and nitrite. Without further parameter adjustments, the model successfully predicted the behavior of 1,4-dioxane during VUV treatment of three groundwaters naturally contaminated with 1,4-dioxane as well as one dechlorinated tap water sample supplemented with 1,4-dioxane.
\end{abstract}

Keywords: Advanced oxidation process, Bicarbonate, Chloride, Nitrate, Nitrite

\section{Introduction}

1,4-Dioxane has been widely used in many applications as a stabilizing agent and a solvent (Zenker et al. 2003). Although wastewater contaminated with 1,4-dioxane undergoes sewage treatment, 1,4-dioxane is quite difficult to remove via conventional sewage treatment based on biological activity, such as activated sludge treatment (Adams et al. 1994, Abe 1999, Tanabe et al. 2006). Treated water containing 1,4-dioxane is therefore discharged into receiving waters such as rivers, lakes, or the ocean. After being discharged into natural waters, 1,4-dioxane easily finds it way underground (Zenker et al. 2003) since 1,4-dioxane does not interact with soil particles because of its very high hydrophilicity $\left(\log K_{\mathrm{ow}}=-0.27\right.$ (Dietz and Schnoor 2001)). As a result, 1,4-dioxane tends to contaminate groundwaters rather than surface waters (Simazaki et al. 2006). Groundwaters should thus be the target of treatment when it comes to treating drinking water for contamination by 1,4-dioxane in the field. 
Because 1,4-dioxane is categorized as a possible carcinogen according to the International Agency for Research on Cancer (Group 2B), it is regulated in drinking water in many countries. The World Health Organization (WHO) considers $50 \mu \mathrm{g} / \mathrm{L}$ to be an appropriate guideline for 1,4-dioxane in drinking water, and the Japan Ministry of Health, Labour and Welfare regulates it in drinking water at the same concentration as the WHO guideline. The German Federal Environmental Agency has suggested a precautionary limit for weak or non-genotoxic compounds such as 1,4-dioxane at the much lower value of $0.1 \mu \mathrm{g} / \mathrm{L}$ in drinking water (Stepien et al. 2014). Although there is currently no federally enforceable drinking water standard for 1,4-dioxane in the United States (Adamson et al. 2017), many states on their own accord have established drinking water and groundwater guidelines ranging from 0.25 to $77 \mu \mathrm{g} / \mathrm{L}$ (United States Environmental Protection Agency 2017). If the raw waters that enter drinking water treatment plants contain 1,4-dioxane at a higher concentration than these values, the compound must be removed during drinking water treatment.

However, 1,4-dioxane is quite difficult to remove via conventional drinking water treatment consisting of coagulation, sedimentation, and sand filtration (McGuire et al. 1978). Activated carbon adsorption (McGuire et al. 1978) and ozonation under neutral pH (Adams et al. 1994, Barndõk et al. 2014) are also ineffective in removing 1,4-dioxane. Because of the ineffective removal of 1,4-dioxane by conventional drinking water treatment, some full-scale drinking water treatment plants have been forced to close in Japan and the United States (Weimar 1980) because groundwater contaminated with high concentrations of 1,4-dioxane was the raw water for the treatment plants.

To overcome the problem of 1,4-dioxane contamination, advanced oxidation processes (AOPs) have been used to remove 1,4-dioxane and have been reported to successfully decompose 1,4-dioxane. The treatment includes a combination of ozonation and hydrogen peroxide $\left(\mathrm{H}_{2} \mathrm{O}_{2}\right)$ (Adams et al. 1994, Suh and Mohseni 2004), a combination of ozonation and ultraviolet light (UV) (Takahashi et al. 2013), a combination of UV and $\mathrm{H}_{2} \mathrm{O}_{2}$ (Matsushita et al. 2015, Chuang et al. 2017, Patton et al. 2018), a combination of UV and free chlorine (Chuang et al. 2017), a combination of UV and chloramines (Chuang et al. 2017, Patton et al. 2018), a combination of UV and persulfate(Li et al. 2018), and a combination of UV and a photocatalyst (Hill et al. 1997, Coleman et al. 2007, Matsushita et al. 2015). Recently, vacuum ultraviolet (VUV) treatment, one form of AOP, has been reported to effectively decompose 1,4-dioxane economically (Matsushita et al. 2015). Unlike the other AOPs, VUV treatment is quite simple and easy-to-use and requires no chemical addition. The latter characteristic could satisfy the requests of urban water utilities that rely on contaminated groundwater for drinking water because they object to the transportation and storage of chemicals in urban areas.

Some computational models that can predict the behavior of organic micropollutants during VUV treatment have been proposed (Imoberdorf and Mohseni 2012, Crapulli et al. 2014, Bagheri and Mohseni 2017, Xie et al. 2018). However, these models have taken into account only bicarbonate and natural organic matter (NOM) to assess the effects of water matrices; other water matrices have not been included in these models.

The goal of the present study was to develop a versatile computational model that took into consideration the effects of coexisting inorganic ions found ubiquitously in natural groundwaters to predict the decomposition of 1,4-dioxane during VUV treatment. We first conducted decomposition experiments with 1,4-dioxane and different concentrations of coexisting inorganic ions to identify the inorganic ions that affected the decomposition. Next, we developed a prediction model consisting of 31 ordinary differential equations with respect to time that had been translated from 84 reactions (10 photochemical and 74 chemical reactions) among 31 chemical species. Some of the model parameters were determined by fitting the predicted values to the observed ones. Finally, to validate the model, we predicted the decomposition curves of 1,4-dioxane in three groundwaters naturally contaminated with 1,4-dioxane without any further parameter fitting. We then discuss the mechanisms of 1,4-dioxane removal during VUV treatment. 


\section{Materials and methods}

\subsection{Raw waters}

To validate our model, we used five types of waters (Table 1), three groundwaters (GW1-3), a river water (RW), and a dechlorinated tap water (DTW). The GW1-3 samples were withdrawn from the raw water inputs to full-scale drinking water treatment plants (Tachikawa, Japan) and stored at $4{ }^{\circ} \mathrm{C}$ until use. No 1,4-dioxane was artificially added to the groundwaters in our laboratory at Hokkaido University (Sapporo, Japan) for the experiments because the groundwaters had already been contaminated with 1,4-dioxane. A river water was withdrawn from the raw water input to a full-scale drinking water treatment plant (Ebetsu, Japan) and stored at $4{ }^{\circ} \mathrm{C}$ until use. The RW sample was prepared by passing the river water through a membrane filter having pores of $0.5 \mu \mathrm{m}$ (PTFE, Toyo Roshi Kaisha, Ltd., Tokyo, Japan), adjusting the $\mathrm{pH}$ at 7.8 with $\mathrm{NaOH}$, and then adding 1,4-dioxane (Fujifilm Wako Pure Chemical Corp., Osaka, Japan) at approximately $100 \mu \mathrm{g} / \mathrm{L}$. DTW was prepared by passing tap water withdrawn at our laboratory through an activated carbon cartridge filter (TCC-WH-T0CP, Toyo Roshi Kaisha) to remove residual free chlorine, adjusting the $\mathrm{pH}$ at 7.8 with $\mathrm{NaOH}$, and then adding 1,4-dioxane at approximately $100 \mu \mathrm{g} / \mathrm{L}$. We confirmed that there was no free chlorine in the DTW by using the $N, N$-diethyl-p-phenylenediamine colorimetric assay (American Public Health Association/American Water Works Association/Water Environment Federation 2005) for residual chlorine. The raw water for the DTW came from the Toyohira River at Sapporo, Japan.

To roughly investigate the effects of coexisting ions on 1,4-dioxane decomposition, $\mathrm{NaHCO}_{3}$ (for $\mathrm{HCO}_{3}^{-}$), $\mathrm{NaNO}_{3}$ (for $\mathrm{NO}_{3}^{-}$), and $\mathrm{NaCl}$ (for $\mathrm{Cl}^{-}$) were serially added to DTW at concentrations equal to those found in GW1 (Table 1) to prepare three DTW-based waters (DTWHCO3, DTW $\mathrm{HCO}_{3}+\mathrm{NO} 3$, and DTW $\mathrm{HCO}_{+\mathrm{NO}}+\mathrm{Cl}$, respectively).

To more precisely quantify the effects of the inorganic ions on 1,4-dioxane decomposition, we conducted further experiments with Milli- ${ }^{\circledR}$ water as a base medium. Phosphate buffer $(500 \mu \mathrm{M}$, $\mathrm{pH} 7.8, \mathrm{NaH}_{2} \mathrm{PO}_{4} / \mathrm{Na}_{2} \mathrm{HPO}_{4}$ ) was prepared with Milli-Q water (Milli-Q Advantage, Millipore Co., Bedford, MA, USA) supplemented with different concentrations of either $\mathrm{NaHCO}_{3}$ (for $\mathrm{HCO}_{3}{ }^{-}$), $\mathrm{NaNO}_{3}$ (for $\mathrm{NO}_{3}^{-}$), $\mathrm{NaNO}_{2}\left(\right.$ for $\mathrm{NO}_{2}^{-}$), or $\mathrm{NaCl}\left(\right.$ for $\mathrm{Cl}^{-}$). Then 1,4-dioxane was added at $100 \mu \mathrm{g} / \mathrm{L}$ to obtain Milli-Q-based waters.

\subsection{Decomposition of 1,4-dioxane in an experimental flow-through VUV reactor}

VUV treatments were conducted with a raw water tank, a pump, and a reactor (Aqua Solutions, UPM-18548-3B, Ube Industries, Ltd., Tokyo, Japan) (Fig. 1). The reactor (14 L) was horizontally divided by walls equipped with annular vessels $(0.13 \mathrm{~L}$ each) into 5 chambers with the same volume. VUV lamps (NNI60/35XL, Heraeus Holding GmbH, Hanau, Germany; 65 W; 185-nm VUV light, $21 \mathrm{~mW} / \mathrm{cm}^{2} ; 254-\mathrm{nm}$ UV light, $51 \mathrm{~mW} / \mathrm{cm}^{2}$, measured on the surface of the lamp), which had been turned on and allowed to warm up prior to the experiment, were inserted inside the inner wall of the annular tube vessel. The 5 chambers and 4 annular tube vessels separating them subjected the water to three types of treatment (Reactor1, Reactor2, and Reactor3). Both the inner and outer walls of the annular tube vessels transmitted both UV $(\lambda=254 \mathrm{~nm})$ and VUV light $(\lambda=185 \mathrm{~nm})$. Reactor 1 was the inside of the annular tube vessels. Reactor2 was located before the first and after the fourth of the annular tube vessels, whereas Reactor 3 was located after the first and before the fourth of the annular tube vessels. The water in Reactor 3 was irradiated with two VUV lamps, but the water in Reactor2 was irradiated with only one VUV lamp.

Raw water $(100 \mathrm{~L})$ was stored in a raw water tank and then pumped into the reactor at a constant flow rate of $5 \mathrm{~L} / \mathrm{min}$ in a single path mode at room temperature. The water was forced to pass through the annular tube vessels (Reactor 1 ) between the inner and outer walls from the bottom to the top, and then to the next chamber (Reactor2 or Reactor 3 ). Finally, the treated water was discharged from Outlet 5. Samples were withdrawn from Outlets 1-5, and the concentrations of 1,4-dioxane in the samples were measured. Dividing the 1,4-dioxane concentrations in each outlet by the concentration in Outlet 1 gave the residual ratios of 1,4-dioxane. The VUV and UV doses of 
the system were determined by chemical actinometry in accord with the methods described by Heit et al. (1998) and Rahn (1997), respectively. The VUV photon dose in Reactor1, Reactor2, and Reactor3 were 41, 0.084, and $0.17 \mu$ moles $/(\mathrm{L} \cdot \mathrm{s})$, respectively, whereas the UV photon doses in Reactor $_{1}$, Reactor 2 , and Reactor 3 were $86,1.0$, and $2.0 \mu \mathrm{moles} /(\mathrm{L} \cdot \mathrm{s})$, respectively.

\subsection{Batch decomposition experiments of 1,4-dioxane for evaluating the effects of Cl-related radicals}

To confirm whether or not the Cl-related radicals $\left(\mathrm{Cl} \bullet\right.$ and $\left.\mathrm{Cl}_{2} \bullet^{-}\right)$contributed to the decomposition of 1,4-dioxane during VUV treatment, we conducted a simple batch experiment. 1,4-Dioxane was dissolved at a concentration of approximately $100 \mu \mathrm{g} / \mathrm{L}$ in a phosphate buffer $(20 \mathrm{mM}, \mathrm{pH} 7.8)$ containing $4000 \mu \mathrm{M}$ of chloride (as $\mathrm{NaCl}$ ). The solution was poured into two beakers, one of which was further supplemented with $500 \mu \mathrm{M}$ of nitrobenzene (Fujifilm Wako Pure Chemical). Nitrobenzene has been reported to react only with $\mathrm{HO} \bullet$ but not with Cl-related radicals (Watts and Linden 2007, Fang et al. 2014) and was accordingly used as an HO• scavenger. The solutions were irradiated in a reactor with a VUV lamp (NNI60/35XL, Heraeus) placed $20 \mathrm{~cm}$ from the top of the solution, which was stirred with a magnetic stir bar. Prior to being filled, the reactor was purged with $\mathrm{N}_{2}$ gas to suppress the effect of oxygen in the atmosphere on the transmission of the VUV light. The samples were withdrawn from the beakers at predetermined intervals, and the 1,4-dioxane concentrations in the samples were measured.

\subsection{Quantification methods}

Concentrations of 1,4-dioxane were measured with a gas chromatograph mass spectrometer (GCMS; QP2010 Plus, Shimadzu Corporation, Kyoto, Japan) equipped with a purge-and-trap sample concentrator (AQUA PT 5000J Plus, GL Science Inc., Tokyo, Japan). A capillary column (HP-5MS; length $30 \mathrm{~m}$, i.d. $250 \mu \mathrm{m}$, thickness $0.25 \mu \mathrm{m}$, Agilent Technologies, Palo Alto, CA, USA) was used for sample separation. The temperatures of the ion source, injector, and transfer line were controlled at 200,180 , and $180^{\circ} \mathrm{C}$, respectively. GC-MS was performed in the selected ion monitoring (SIM) mode with d8-1,4-dioxane (Fujifilm Wako Pure Chemical) as an internal standard; the detected fragment ions of 1,4-dioxane and d8-1,4-dioxane occurred at $\mathrm{m} / \mathrm{z} 88$ and 96 , respectively.

Concentrations of cations were measured with an ion chromatograph (CS-1000, Dionex, Sunnyvale, CA, USA) equipped with a separation column (IonPac CS16, Dionex). Concentrations of anions were measured with an ion chromatograph (DX-120, Dionex) equipped with a separation column (IonPac AS14, Dionex). Dissolved organic carbon was quantified with a total organic carbon analyzer (Sievers 900, GE Analytical Instruments, Boulder, CO, USA) after passing the samples through a membrane (PTFE, $\phi=0.2 \mu \mathrm{m}$, Toyo Roshi Kaisha).

\subsection{Model analysis}

We developed a computational model to predict the decomposition of 1,4-dioxane via VUV treatment. The model reactor consisted of chambers and vessels as shown in Fig. 1. The computer program divided the model reactor into the appropriate number of compartments along the flow direction. Flow was assumed to be continuous between compartments, and complete mixing was assumed in each compartment. The liquid migrated along the flow direction according to one-dimensional plug flow. The UV/VUV irradiation was assumed to be distributed uniformly in each compartment.

The model consisted of 10 photochemical reactions (Eqs. S1-S10 in SI) and 74 chemical reactions (Eqs. S11-S84). The reactions were modeled by 31 ordinary differential equations with respect to time that described the rates of change of 31 chemical species. We solved the system of ordinary differential equations by using Gear's stiff method (DIVPAG) in the International Mathematics and Statistics Library (IMSL, Visual Numerics, Houston, TX, USA) after deriving the analytical Jacobian of the equations. We determined model parameters by minimizing the sum of squares of the differences between the calculated and observed values with a quasi-Newton method and a finite-difference gradient method (DUMINF) from the IMSL library. 


\section{Results and discussion}

\subsection{Identifying the ions that influence 1,4-dioxane decomposition during VUV treatment}

In DTW (red crosses, Fig. 2), 1,4-dioxane rapidly decomposed with VUV treatment, and the residual ratio finally reached approximately 0.02 at a VUV photon dose of $270 \mu \mathrm{mole} / \mathrm{L}$. In contrast, even at the same VUV dose, the residual ratio was 0.22 in GW1 (blue circles), much higher than in DTW. Therefore, 1,4-dioxane decomposition was suppressed in GW1. Decomposition of organic micropollutants during VUV irradiation are reportedly influenced by some water quality characteristics. Dissolved oxygen (DO) has been reported to affect the decomposition of organics during VUV treatment (Shirayama et al. 2001, Alapi and Dombi 2007, Kutschera et al. 2009), but the DO concentration was almost the same in the DTW $(9.0 \mathrm{mg} / \mathrm{L})$ and GW1 $(8.9 \mathrm{mg} / \mathrm{L})$ used in the present study. Solution $\mathrm{pH}$ also impacts the decomposition of organics during VUV irradiation (Kutschera et al. 2009), but the pHs of DTW and GW1 were both $\mathrm{pH}$ 7.8.

To investigate why 1,4-dioxane decomposition was suppressed in GW1, we added some inorganic ions serially to DTW and conducted irradiation experiments on the waters. Suppression of 1,4-dioxane decomposition when $\mathrm{NaHCO}_{3}$ was added to DTW (DTWHCO3, orange triangles in Fig. 2 ) indicated that either sodium or bicarbonate or both suppressed the decomposition. The further suppression of the decomposition when $\mathrm{NaNO}_{3}$ was added to DTW $\mathrm{HCO}_{3}$ (DTW $\mathrm{HCO}_{3+\mathrm{NO}}$, yellow diamonds in Fig. 2) indicated that either sodium or nitrate or both suppressed the decomposition. The further suppression of the decomposition when $\mathrm{NaCl}$ was added to $\mathrm{DTW}_{\mathrm{HCO}+\mathrm{NO} 3}$ (DTW $\mathrm{HCO}_{3}+\mathrm{NO}^{+} \mathrm{Cl}$, green squares in Fig. 2) indicated that either sodium or chloride or both suppressed the decomposition.

To determine whether or not sodium ions suppressed the decomposition of 1,4-dioxane, we supplemented DTW with either $\mathrm{NaCl}, \mathrm{CaCl}_{2}$, or $\mathrm{MgCl}_{2}$ at similar chloride concentrations $(800-1000 \mu \mathrm{M})$ and subjected the water to VUV treatment. The decomposition rates of 1,4-dioxane were almost the same (Fig. S1), even though the cation concentrations differed among the waters (Fig. S2). These results strongly suggested that decomposition of 1,4-dioxane was affected by the anion and not by the cations. Therefore, the suppressions observed in the experiments with the DTW-based waters were probably due to the anions, namely bicarbonate, nitrate, and chloride. Moreover, the fact that the rate of decomposition of 1,4-dioxane was almost the same in $\mathrm{DTW}_{\mathrm{HCO} 3+\mathrm{NO} 3+\mathrm{Cl}}$ and $\mathrm{GW} 1$ indicated that the suppression was completely explained by these three anions. Although NOM has been reported to reduce the decompositions of organic micropollutants by VUV irradiation (Kutschera et al. 2009, Imoberdorf and Mohseni 2012, Wols and Hofman-Caris 2012), the contribution of NOM to the suppression was negligibly small in the present study, probably because the concentrations of DOC in both GW1 and DTW-based waters were very small $(<0.2 \mathrm{mg} / \mathrm{L}$, Table 1). Because 1,4-dioxane contaminates groundwaters rather than river waters (vide supra), it is important to note that DOC may be ignored when predicting the rate of decomposition of 1,4-dioxane in groundwaters because the DOC concentrations in groundwaters are typically much lower than those expected in river waters.

\subsection{Effects of influential ions on 1,4-dioxane decomposition during VUV treatment}

To more precisely quantify the effects of these three anions on 1,4-dioxane decomposition during VUV treatment, we conducted further experiments on Milli-Q-based waters containing each anion at different concentrations. The decrease of the apparent pseudo-first-order decomposition rate constant of 1,4-dioxane with increasing bicarbonate concentration (Fig. 3a) when $\mathrm{NaHCO}_{3}$ was added to the buffered Milli-Q water clearly indicated that bicarbonate contributed to the suppression. Bicarbonate has been reported to react with the hydroxyl radical (HO•) (Imoberdorf and Mohseni 2012, Wols and Hofman-Caris 2012) to form a carbonate radical $\left(\mathrm{CO}_{3}{ }^{-} \bullet\right.$ ) (Eq. S43) (Crittenden et al. 1999, Canonica et al. 2005). Because $\mathrm{CO}_{3}{ }^{-} \bullet$ is approximately 1000 times less reactive than $\mathrm{HO}$ • (Mazellier et al. 2007), the contribution of $\mathrm{CO}_{3}{ }^{-} \bullet$ to the decompositions of target micropollutants is expected to be negligibly small. Bicarbonate therefore reduces the decomposition rates of organic micropollutants during VUV treatment (Kutschera et al. 2009, Imoberdorf and Mohseni 2012). 
The decrease of the apparent pseudo-first-order decomposition rate constant with increasing nitrate concentration (Fig. 3b) when $\mathrm{NaNO}_{3}$ was added to the buffered Milli-Q water suggested that nitrate contributed to the suppression. However, the linearity of the 1,4-dioxane decay curves in the solutions supplemented with either bicarbonate or chloride (Fig. S3) implied that the apparent decomposition rates were constant throughout VUV treatment. In contrast, the decay curve in the presence of nitrate was nonlinear; the apparent decomposition rate in the presence of nitrate decreased with increasing irradiation. Moreover, the concentration of nitrite increased as nitrate decreased during the VUV treatment (Fig. S4). Nitrate was therefore transformed into nitrite. These observations strongly suggested that nitrite rather than nitrate contributed to the suppression of 1,4-dioxane decomposition. Nitrate is transformed to a nitrite radical $\left(\mathrm{NO}_{2} \bullet\right)$ by UV light irradiation (Eq. S6) (Mack and Bolton 1999). Two moles of $\mathrm{NO}_{2} \bullet$ produces one mole of dinitrogen tetroxide (Eq. S74), which is then hydrolyzed to one mole of nitrite and nitrate (Eq. S76) (Mack and Bolton 1999). These reactions have been reported to be very fast (Vione et al. 2009, Zoschke et al. 2014). Some of the nitrate is transformed via these reactions into nitrite by the UV irradiation that occurs concomitantly during VUV treatment. The nitrite concentration therefore increased in the solution supplemented with nitrate during the VUV treatment in the present study. Even though both nitrite (Eq. S71) and nitrate (Eq. S70) react with $\mathrm{HO} \bullet$, the reaction rate constant of nitrite with $\mathrm{HO} \bullet(1.0 \times$ $10^{10} \mathrm{M}^{-1} \mathrm{~s}^{-1}$ (Mack and Bolton 1999)) is $10^{5}$ times that of nitrate $\left(1.0 \times 10^{5} \mathrm{M}^{-1} \mathrm{~s}^{-1}\right.$ (Gonzalez and Braun 1995)). The consumption of $\mathrm{HO} \cdot$ is therefore expected to be negligibly small for nitrate versus nitrite. Accordingly, 1,4-dioxane decomposition is suppressed by nitrite rather than nitrate. The concentration dependence of the suppression of 1,4-dioxane decomposition was in fact confirmed by the experiments with solutions containing different initial nitrite concentrations (Fig. 3c).

The decomposition of 1,4-dioxane was increasingly suppressed by higher chloride concentrations (Fig. 3d). Chloride reacts with $\mathrm{HO} \bullet$ to form ClHO $\bullet^{-}$(Eq. S50), and then Cl-related radicals $\left(\mathrm{Cl} \bullet\right.$ and $\left.\mathrm{Cl}_{2} \bullet^{-}\right)$are generated in subsequent reactions (Eqs. S52 and S53) (Matthew and Anastasio 2006). In UV/free chlorine treatment, Cl-related radicals have been reported to play a partial role in decomposing organic micropollutants (Fang et al. 2014, Guo et al. 2017). However, in the VUV treatment employed in the present study, Cl-related radicals probably did not contribute to the decomposition of 1,4-dioxane because the expected concentrations of Cl-related radicals were much lower than those expected in UV/free chlorine treatment. To investigate whether or not the Cl-related radicals contributed to 1,4-dioxane decomposition, we conducted batch decomposition experiments with an $\mathrm{HO} \bullet$ scavenger (nitrobenzene).

Whereas 1,4-dioxane decomposed in the absence of nitrobenzene during VUV irradiation (open circles, Fig. 4), it did not decompose in the presence of nitrobenzene (solid circles). The observation clearly showed that $\mathrm{HO} \cdot$ alone decomposed 1,4-dioxane, and that reactions with Cl-related radicals (as well as direct photolysis by UV and VUV light) did not decompose 1,4-dioxane directly, even in the presence of the highest concentration of chloride $(4000 \mu \mathrm{M})$ used in the flow-through experiments. Li et al. (2017) reported that the contribution of Cl-related radicals to the decomposition of 1,4-dioxane was quite limited, even in a UV/free chlorine treatment in which the concentrations of Cl-related radicals were much higher than the concentrations that were likely generated in our VUV treatment. They concluded that the major chemical species responsible for the decomposition was $\mathrm{HO} \cdot$. Chloride therefore suppressed the decomposition of 1,4-dioxane during VUV treatment by competitive consumption of $\mathrm{HO} \cdot$. In the present study, the reactions of 1,4-dioxane with Cl-related radicals and direct photolysis by UV and VUV light were both omitted from the model; 1,4-dioxane was assumed to react only with $\mathrm{HO} \cdot$

The order of the extent of suppression of 1,4-dioxane decomposition per mole was nitrite $>>$ bicarbonate $>$ chloride.

\subsection{Model prediction of 1,4-dioxane decomposition during VUV treatment}

We developed the computational model described in section 2.5 to predict the rate of decomposition 
of 1,4-dioxane during VUV treatment. The model consisted of 10 photochemical (Eqs. S1-10) and 74 chemical reactions (Eqs. S11-84). Because the quantum yields for nitrate ( $\Phi_{5}$ and $\Phi_{7}$ in Eqs. S5 and S7, respectively) and nitrite ( $\Phi_{9}$ in Eq. S9) with VUV light had not previously been reported, those parameters were determined by fitting the calculated concentrations of 1,4-dioxane, nitrate, and nitrite to the observed concentrations. Molar absorption coefficients of nitrate and nitrite to the VUV light ( $\mathcal{E}_{185, \mathrm{NO} 3}$ and $\mathcal{E}_{185, \mathrm{NO} 2}$ in Eqs. S5 and S9, respectively) had also not been reported and needed to be determined by the fitting procedure. A reaction rate constant for 1,4-dioxane with $\mathrm{HO} \bullet$ ( $k_{41}$ in Eq. S41) had been proposed (Bagheri and Mohseni 2017, Patton et al. 2017) but was determined in the present study by the fitting procedure. However, even though these 6 parameters were adjusted to give the best agreement between the calculated and observed values in preliminary trials, the modeled values did not fit the observed values well (Figs. S5 and S6). Consequently, three of the most influential parameters, $k_{51}$ (generation rate constant of $\mathrm{HO} \bullet$ from $\mathrm{ClHO} \bullet^{-}$in Eq. S51), $k_{71}$ (reaction rate constant between nitrite and $\mathrm{HO} \bullet$ in Eq. S71), and $k_{75}$ (decomposition rate constant of $\mathrm{N}_{2} \mathrm{O}_{4}$ to $\mathrm{NO}_{2} \bullet$ in Eq. S75), were added to the fitting parameters (9 parameters in total), and then all parameters were simultaneously determined by the fitting procedure.

The results of the fitting (Fig. 5) revealed that the calculation (curvilinear lines) successfully described the 1,4-dioxane decay curves (symbols), even when the concentrations of the inorganic ions differed. Moreover, the fact that the model also successfully described the changes of both nitrate and nitrite concentrations (Fig. S7) indicated that the model could predict the decomposition of 1,4-dioxane during VUV treatment under different ionic conditions. It should be noted that the convergence characteristics of the Newton-type algorithms used in the present study for solving a system of nonlinear equations is highly sensitive to the initial guess of the solution supplied to the algorithm (Luo et al. 2008), and hence algorithms may detect only a local optimum. In the present study, we conducted optimizations with different sets of initial guesses (quantum yields 0.001-0.8; molar absorption coefficients $1-10^{5} \mathrm{M}^{-1} \mathrm{~cm}^{-1}$; decomposition rate constants $10^{6}$ to $5 \times 10^{10} \mathrm{M}^{-1} \mathrm{~s}^{-1}$ ), all of which resulted in the same optimizer. Optimizations with sets of initial guesses that were not within these ranges resulted in different optimizers, but the values to be minimized (i.e., the sum of squares of the differences between the calculated and observed values) were larger than the values with the unique optimizer. The results therefore demonstrated that the parameter values corresponded to a global rather than local optimum.

To assess the adequateness of our model, 1,4-dioxane decomposition experiments were further conducted with two groundwaters naturally contaminated with 1,4-dioxane (GW2 and 3) and a river water that had been artificially supplemented with 1,4-dioxane (RW). We tried to predict the behavior of 1,4-dioxane in the different natural waters (GW1-3 and RW) and in dechlorinated tap water that had been artificially supplemented with 1,4-dioxane (DTW). The nine parameters in the model had previously been determined by using the datasets illustrated in Figs. 5 and S7. In the prediction, further fitting was not conducted. The model simulation successfully predicted the behavior of 1,4-dioxane as a function of VUV dose for GW1-3 and DTW (Fig. 6), even without further parameter fitting to the dataset. The results clearly showed that the computational model developed in the present study was able to describe the effects of inorganic ions on the chemical reactions expected during VUV treatment-no matter whether or not the reactions were directly related to the decomposition of 1,4-dioxane-and that the model could successfully predict the rate of decomposition of 1,4-dioxane in waters containing different concentrations of inorganic ions. However, the model overestimated the decomposition of 1,4-dioxane in RW. Actually, the sum of squares of the differences between the calculated and observed values, which was calculated as an index of the extent of fitting, for RW (0.11) was much larger than those for the other waters $(0.054$, 0.012, 0.0089, and 0.020 for GW1, GW2, GW3, and DTW, respectively). Concentration of DOC in RW was more than one order of magnitude larger than those in the other waters (Table 1). NOM has been reported to reduce the decomposition of organic micropollutants by VUV irradiation (Kutschera et al. 2009, Imoberdorf and Mohseni 2012, Wols and Hofman-Caris 2012), but our model included no reactions involving NOM. Our model was difficult to apply to waters containing 
high DOC such as typical river waters, but was able to predict 1,4-dioxane decay in waters containing very low DOC such as typical groundwaters.

To confirm the economic feasibility of VUV treatment, we calculated EE/O values, that is, the amount of electric energy required to reduce the concentration of a target compound (1,4-dioxane) in $1 \mathrm{~m}^{3}$ of contaminated water by one order of magnitude (Bolton et al. 2001), as follows:

$$
\mathrm{EE} / \mathrm{O}=\frac{P}{F \times \log \left(c_{0} / c\right)}
$$

where $P$ is electric power $(\mathrm{kW}), F$ is flow rate $\left(\mathrm{m}^{3} / \mathrm{h}\right), c_{0}$ is 1,4 -dioxane concentration at Outlet 1 , and $c$ is 1,4-dioxane concentration at Outlet 5. The EE/O values for GW1-3, RW, and DTW were $1.2,1,3,1.8,1.4$, and $0.41 \mathrm{kWh} /\left(\mathrm{m}^{3} \cdot\right.$ order $)$, respectively. Systems are considered to be economically feasible when the EE/O value is less than 10 (Andrews et al. 1995). On the basis of this criterion, VUV treatment is economically feasible for 1,4-dioxane decomposition in all waters tested.

\section{Conclusions}

1. Decomposition of 1,4-dioxane during VUV treatment is suppressed by inorganic ions ubiquitously found in natural groundwaters, namely bicarbonate, chloride, and nitrate. Whereas bicarbonate and chloride directly suppress the decomposition of 1,4-dioxane, nitrate becomes influential after it is transformed into nitrite during VUV treatment. The order of the extent of suppression per mole is nitrite $>>$ bicarbonate $>$ chloride.

2. Experiments with an $\mathrm{HO} \cdot$ scavenger (nitrobenzene) revealed that 1,4-dioxane is decomposed by $\mathrm{HO} \bullet$ during VUV treatment. The Cl-related radicals $\left(\mathrm{Cl} \bullet\right.$ and $\left.\mathrm{Cl}_{2} \bullet^{-}\right)$do not react with 1,4-dioxane.

3. A computational model that incorporated the effects of the inorganic ions on the chemical reactions expected during VUV treatment-no matter whether or not the reactions were directly related to the decomposition of 1,4-dioxane - successfully predicted the decomposition of 1,4-dioxane during VUV treatment in three groundwaters naturally contaminated with 1,4-dioxane and one dechlorinated tap water artificially supplemented with 1,4-dioxane without further parameter fitting. This result clearly demonstrated the adequacy of the model to predict the decomposition of 1,4-dioxane during treatment of contaminated groundwater.

\section{Acknowledgments}

This research was supported in part by a Grant-in-Aid for Scientific Research (S) (16H06362) from the Japan Society for the Promotion of Science.

\section{References}

Abe, A. (1999) Distribution of 1,4-dioxane in relation to possible sources in the water environment. Science of The Total Environment 227(1), 41-47.

Adams, C.D., Scanlan, P.A. and Secrist, N.D. (1994) Oxidation and biodegradability enhancement of 1,4-dioxane using hydrogen peroxide and ozone. Environmental Science \& Technology 28(11), 1812-1818.

Adamson, D.T., Piña, E.A., Cartwright, A.E., Rauch, S.R., Hunter Anderson, R., Mohr, T. and Connor, J.A. (2017) 1,4-Dioxane drinking water occurrence data from the third unregulated contaminant monitoring rule. Science of The Total Environment 596-597, 236-245.

Alapi, T. and Dombi, A. (2007) Comparative study of the UV and UV/VUV-induced photolysis of phenol in aqueous solution. Journal of Photochemistry and Photobiology A: Chemistry 188(2), 409-418.

American Public Health Association/American Water Works Association/Water Environment Federation (2005) Standard Methods for Examination of Water and Wastewater. 
Andrews, S.A., Huck, P.M., Chute, A.J., Bolton, J.R. and Anderson, W.A. (1995) UV oxidation for drinking water - Feasibility studies for addressing specific water quality issues, New Orleans, LA, USA.

Bagheri, M. and Mohseni, M. (2017) Pilot-scale treatment of 1,4-dioxane contaminated waters using $185 \mathrm{~nm}$ radiation: Experimental and CFD modeling. Journal of Water Process Engineering 19, 185-192.

Barndõk, H., Cortijo, L., Hermosilla, D., Negro, C. and Blanco, Á. (2014) Removal of 1,4-dioxane from industrial wastewaters: Routes of decomposition under different operational conditions to determine the ozone oxidation capacity. Journal of Hazardous Materials 280, 340-347.

Bolton, J.R., Bircher, K.G., Tumas, W. and Tolman, C.A. (2001) Figures-of-merit for the technical development and application of advanced oxidation technologies for both electric- and solar-driven systems (IUPAC Technical Report). Pure and Applied Chemistry 73(4), 627-637.

Canonica, S., Kohn, T., Mac, M., Real, F.J., Wirz, J. and von Gunten, U. (2005) Photosensitizer method to determine rate constants for the reaction of carbonate radical with organic compounds. Environmental Science \& Technology 39(23), 9182-9188.

Chuang, Y.-H., Chen, S., Chinn, C.J. and Mitch, W.A. (2017) Comparing the UV/monochloramine and $\mathrm{UV} /$ free chlorine advanced oxidation processes (AOPs) to the UV/hydrogen peroxide AOP under scenarios relevant to potable reuse. Environmental Science \& Technology 51(23), 13859-13868.

Coleman, H.M., Vimonses, V., Leslie, G. and Amal, R. (2007) Degradation of 1,4-dioxane in water using $\mathrm{TiO}_{2}$ based photocatalytic and $\mathrm{H}_{2} \mathrm{O}_{2} / \mathrm{UV}$ processes. Journal of Hazardous Materials 146(3), 496-501.

Crapulli, F., Santoro, D., Sasges, M.R. and Ray, A.K. (2014) Mechanistic modeling of vacuum UV advanced oxidation process in an annular photoreactor. Water Research 64, 209-225.

Crittenden, J.C., Hu, S., Hand, D.W. and Green, S.A. (1999) A kinetic model for $\mathrm{H}_{2} \mathrm{O}_{2} / \mathrm{UV}$ process in a completely mixed batch reactor. Water Research 33(10), 2315-2328.

Dietz, A.C. and Schnoor, J.L. (2001) Advances in phytoremediation. Environmental Health Perspectives 109(Suppl 1), 163-168.

Fang, J., Fu, Y. and Shang, C. (2014) The roles of reactive species in micropollutant degradation in the UV/free chlorine system. Environmental Science \& Technology 48(3), 1859-1868.

Gonzalez, M.C. and Braun, A.M. (1995) VUV photolysis of aqueous solutions of nitrate and nitrite. Research on Chemical Intermediates 21(8), 837-859.

Guo, K., Wu, Z., Shang, C., Yao, B., Hou, S., Yang, X., Song, W. and Fang, J. (2017) Radical chemistry and structural relationships of PPCP degradation by UV/chlorine treatment in simulated drinking water. Environmental Science \& Technology 51(18), 10431-10439.

Heit, G., Neuner, A., Saugy, P.-Y. and Braun, A.M. (1998) Vacuum-UV (172 nm) actinometry. The quantum yield of the photolysis of water. The Journal of Physical Chemistry A 102(28), 5551-5561.

Hill, R.R., Jeffs, G.E. and Roberts, D.R. (1997) Photocatalytic degradation of 1,4-dioxane in aqueous solution. Journal of Photochemistry and Photobiology A: Chemistry 108(1), 55-58.

Imoberdorf, G.E. and Mohseni, M. (2012) Kinetic study and modeling of the vacuum-UV photoinduced degradation of 2,4-D. Chemical Engineering Journal 187, 114-122.

Kutschera, K., Börnick, H. and Worch, E. (2009) Photoinitiated oxidation of geosmin and 2-methylisoborneol by irradiation with $254 \mathrm{~nm}$ and $185 \mathrm{~nm}$ UV light. Water Research 43(8), 2224-2232.

Li, W., Jain, T., Ishida, K. and Liu, H. (2017) A mechanistic understanding of the degradation of trace organic contaminants by $\mathrm{UV} /$ hydrogen peroxide, $\mathrm{UV} /$ persulfate and $\mathrm{UV} /$ free chlorine for water reuse. Environmental Science: Water Research \& Technology 3(1), 128-138.

Li, W., Patton, S., Gleason, J.M., Mezyk, S.P., Ishida, K.P. and Liu, H. (2018) UV photolysis of chloramine and persulfate for 1,4-dioxane removal in reverse-osmosis permeate for potable water reuse. Environmental Science \& Technology 52(11), 6417-6425. 
Luo, Y.-Z., Tang, G.-J. and Zhou, L.-N. (2008) Hybrid approach for solving systems of nonlinear equations using chaos optimization and quasi-Newton method. Applied Soft Computing 8(2), 1068-1073.

Mack, J. and Bolton, J.R. (1999) Photochemistry of nitrite and nitrate in aqueous solution: a review. Journal of Photochemistry and Photobiology A: Chemistry 128(1), 1-13.

Matsushita, T., Hirai, S., Ishikawa, T., Matsui, Y. and Shirasaki, N. (2015) Decomposition of 1,4-dioxane by vacuum ultraviolet irradiation: Study of economic feasibility and by-product formation. Process Safety and Environmental Protection 94, 528-541.

Matthew, B.M. and Anastasio, C. (2006) A chemical probe technique for the determination of reactive halogen species in aqueous solution: Part 1 - bromide solutions. Atmospheric Chemistry and Physics 6(9), 2423-2437.

Mazellier, P., Busset, C., Delmont, A. and De Laat, J. (2007) A comparison of fenuron degradation by hydroxyl and carbonate radicals in aqueous solution. Water Research 41(20), 4585-4594.

McGuire, M.J., Suffet, I.H. and Radziul, J.V. (1978) Assessment of unit processes for the removal of trace organic compounds from drinking water. Journal American Water Works Association 70(10), 565-572.

Patton, S., Li, W., Couch, K.D., Mezyk, S.P., Ishida, K.P. and Liu, H. (2017) Impact of the ultraviolet photolysis of monochloramine on 1,4-dioxane removal: new insights into potable water reuse. Environmental Science \& Technology Letters 4(1), 26-30.

Patton, S., Romano, M., Naddeo, V., Ishida, K.P. and Liu, H. (2018) Photolysis of mono- and dichloramines in UV/hydrogen peroxide: effects on 1,4-dioxane removal and relevance in water reuse. Environmental Science \& Technology 52(20), 11720-11727.

Rahn, R.O. (1997) Potassium iodide as a chemical actinometer for $254 \mathrm{~nm}$ radiation: use of iodate as an electron scavenger. Photochemistry and Photobiology 66(4), 450-455.

Shirayama, H., Tohezo, Y. and Taguchi, S. (2001) Photodegradation of chlorinated hydrocarbons in the presence and absence of dissolved oxygen in water. Water Research 35(8), 1941-1950.

Simazaki, D., Asami, M., Nishimura, T., Kunikane, S., Aizawa, T. and Magara, Y. (2006) Occurrence of 1,4-dioxane and MTBE in drinking water sources in Japan. Water Science and Technology: Water Supply 6(2), 47-53.

Stepien, D.K., Diehl, P., Helm, J., Thoms, A. and Püttmann, W. (2014) Fate of 1,4-dioxane in the aquatic environment: From sewage to drinking water. Water Research 48, 406-419.

Suh, J.H. and Mohseni, M. (2004) A study on the relationship between biodegradability enhancement and oxidation of 1,4-dioxane using ozone and hydrogen peroxide. Water Research 38(10), 2596-2604.

Takahashi, N., Hibino, T., Torii, H., Shibata, S., Tasaka, S., Yoneya, J., Matsuda, M., Ogasawara, H., Sugimoto, K. and Fujioka, T. (2013) Evaluation of $\mathrm{O}_{3} / \mathrm{UV}$ and $\mathrm{O}_{3} / \mathrm{H}_{2} \mathrm{O}_{2}$ as practical advanced oxidation processes for degradation of 1,4-dioxane. Ozone: Science \& Engineering 35(5), 331-337.

Tanabe, A., Tsuchida, Y., Ibaraki, T. and Kawata, K. (2006) Impact of 1,4-dioxane from domestic effluent on the Agano and Shinano Rivers, Japan. Bulletin of Environmental Contamination and Toxicology 76(1), 44-51.

United States Environmental Protection Agency (2017) Technical Fact Sheet - 1,4-Dioxane.

Vione, D., Khanra, S., Man, S.C., Maddigapu, P.R., Das, R., Arsene, C., Olariu, R.-I., Maurino, V. and Minero, C. (2009) Inhibition vs. enhancement of the nitrate-induced phototransformation of organic substrates by the $\cdot \mathrm{OH}$ scavengers bicarbonate and carbonate. Water Research 43(18), 4718-4728.

Watts, M.J. and Linden, K.G. (2007) Chlorine photolysis and subsequent OH radical production during UV treatment of chlorinated water. Water Research 41(13), 2871-2878.

Weimar, R.A. (1980) Prevent groundwater contamination before it's too late. Water and Wastes Engineering 17, 30-33.

Wols, B.A. and Hofman-Caris, C.H.M. (2012) Review of photochemical reaction constants of 
organic micropollutants required for UV advanced oxidation processes in water. Water Research 46(9), 2815-2827.

Xie, P., Yue, S., Ding, J., Wan, Y., Li, X., Ma, J. and Wang, Z. (2018) Degradation of organic pollutants by Vacuum-Ultraviolet (VUV): Kinetic model and efficiency. Water Research 133, 69-78.

Zenker, M.J., Borden, R.C. and Barlaz, M.A. (2003) Occurrence and treatment of 1,4-dioxane in aqueous environments. Environmental Engineering Science 20(5), 423-432.

Zoschke, K., Börnick, H. and Worch, E. (2014) Vacuum-UV radiation at $185 \mathrm{~nm}$ in water treatment - A review. Water Research 52, 131-145. 
Table 1 Water quality of natural groundwaters (GW1-3), natural river water (RW), and dechlorinated tap water (DTW) used for validating the prediction model.

\begin{tabular}{|c|c|c|c|c|c|c|c|c|c|c|c|c|c|}
\hline & $\mathrm{pH}$ & $\begin{array}{l}\mathrm{DOC} \\
\mathrm{mg} / \mathrm{L}\end{array}$ & \multicolumn{10}{|c|}{$\mu \mathrm{g} / \mathrm{L}$} & $\begin{array}{c}\text { 1,4-dioxane } \\
\mu \mathrm{g} / \mathrm{L}\end{array}$ \\
\hline GW1 & 7.8 & 0.06 & 588 & 16 & 0 & 259 & 531 & 1008 & 145 & 0 & 82 & 440 & 95 \\
\hline GW2 & $7.8^{1)}$ & 0.07 & 607 & 18 & 0 & 374 & 765 & 655 & 314 & 0 & 231 & 450 & 55 \\
\hline GW3 & $7.8^{1)}$ & 0.09 & 666 & 35 & 0 & 505 & 1146 & 605 & 452 & 0 & 354 & 1050 & 36 \\
\hline RW & $7.8^{1)}$ & 2.2 & 700 & 60 & 0 & 162 & 296 & 460 & 54 & 8 & 9 & 380 & $104^{2)}$ \\
\hline DTW & $7.8^{1)}$ & 0.2 & 768 & 44 & 0 & 73 & 293 & 482 & 17 & 0 & 139 & 140 & $100^{2)}$ \\
\hline
\end{tabular}

1) Artificially adjusted with $\mathrm{NaOH}$. The concentration of $\mathrm{Na}^{+}$accordingly increased with the adjustment. The values indicated in the table are the post-adjustment values.

2) Artificially added by using a chemical standard. 

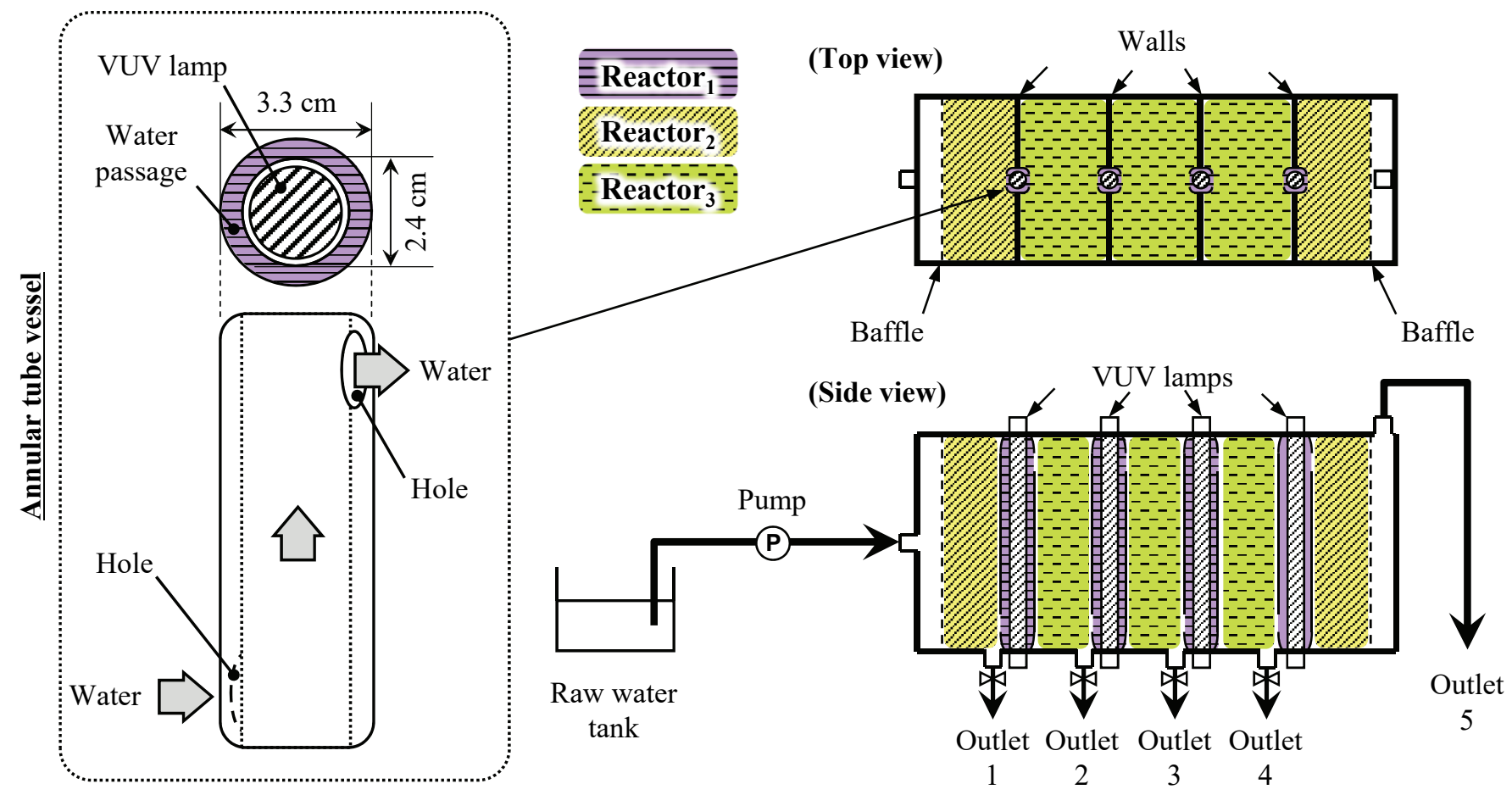

Fig. 1 Design of experimental VUV reactor. 


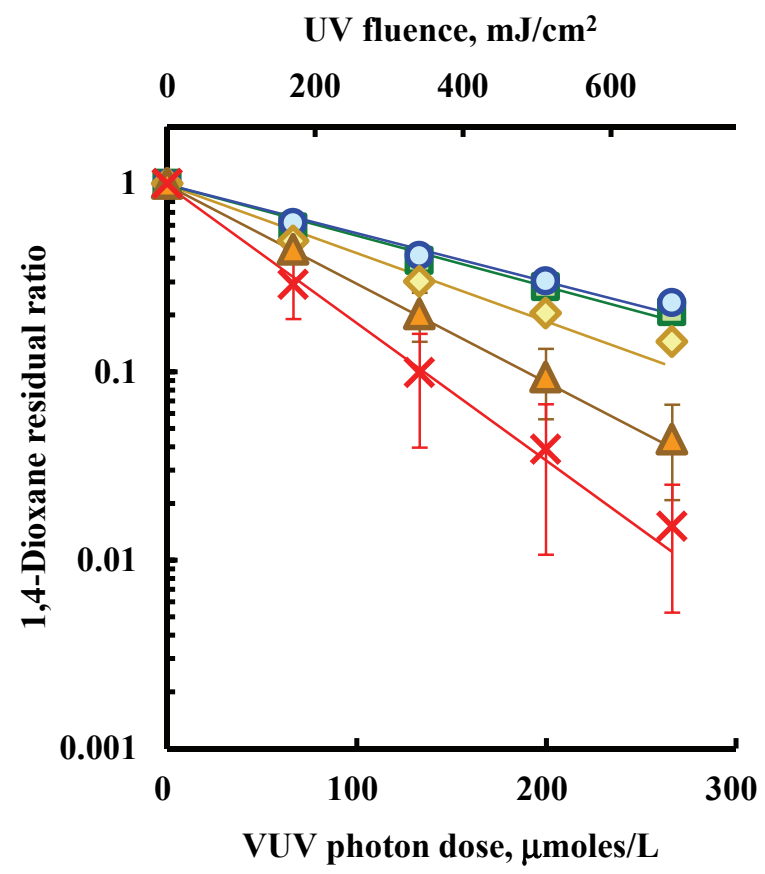

Fig. 2 Change in 1,4-dioxane residual ratio with VUV irradiation. Blue circles, GW1; green squares, DTW $+\mathrm{HCO}_{3}^{-}+\mathrm{NO}_{3}^{-}+\mathrm{Cl}^{-}$; yellow diamonds, $\mathrm{DTW}+\mathrm{HCO}_{3}^{-}+\mathrm{NO}_{3}^{-}$; orange triangles, DTW + $\mathrm{HCO}_{3}^{-}$; red crosses, DTW. Error bars indicate standard deviations of at least three experiments. 

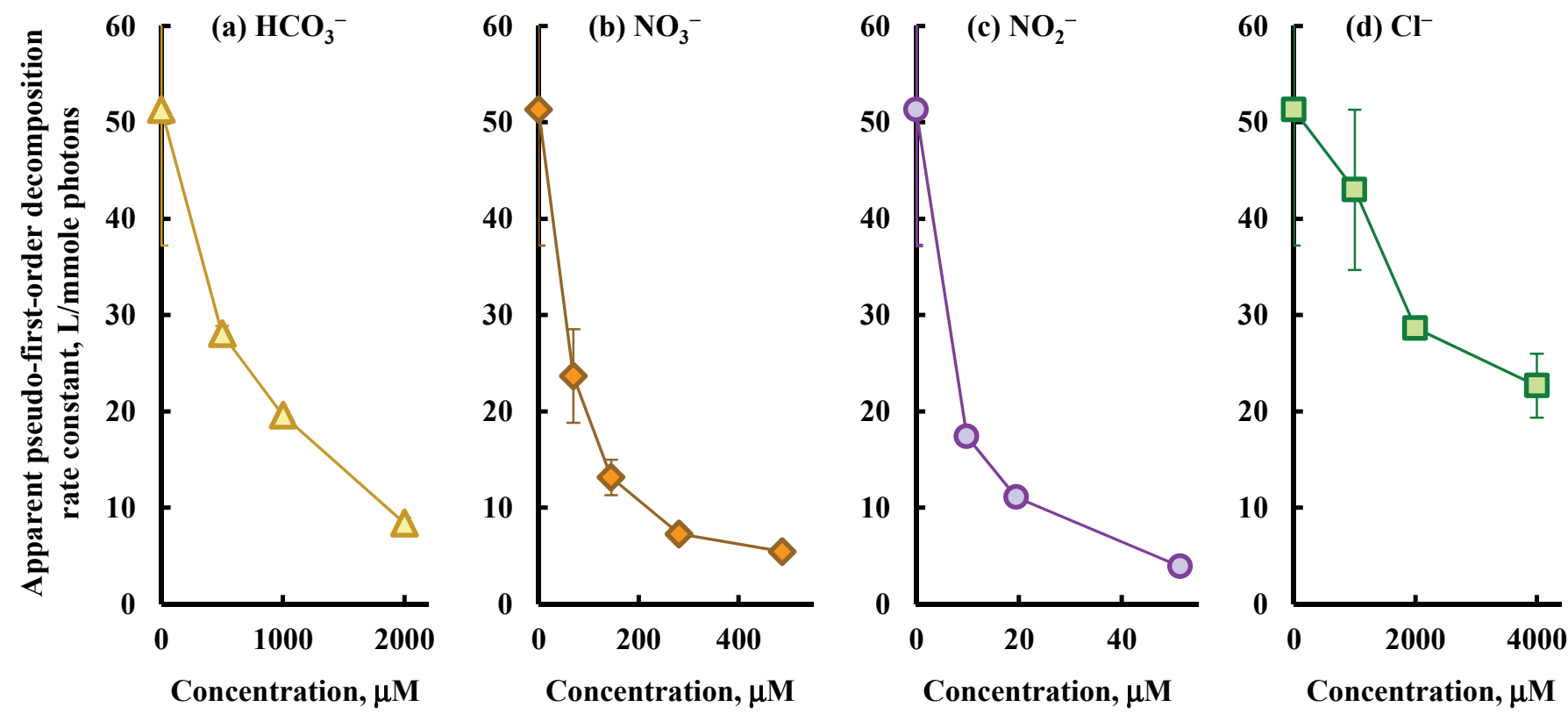

Fig. 3 Effects of concentrations of (a) $\mathrm{HCO}_{3}^{-}$, (b) $\mathrm{NO}_{3}^{-}$, (c) $\mathrm{NO}_{2}^{-}$, and (d) $\mathrm{Cl}^{-}$in buffered Milli-Q water on apparent pseudofirst-order decomposition rate constant of 1,4-dioxane during VUV treatment. Error bars indicate standard deviations of at least two experiments. 


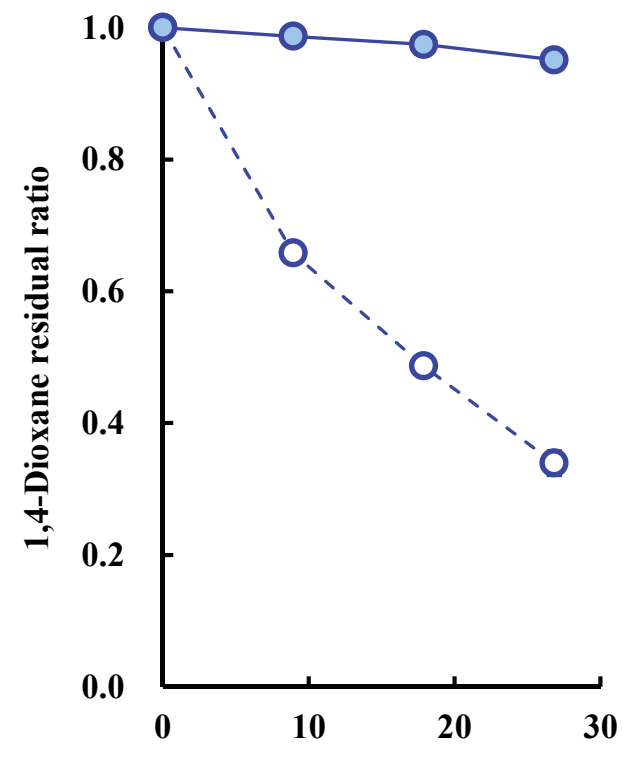

VUV photon dose, $\mu$ moles/L

Fig. 4 Complete suppression of 1,4dioxane decomposition during VUV irradiation by adding an $\mathrm{HO}$ - scavenger (nitrobenzene, $500 \mu \mathrm{M}$ ). Solid and open circles indicate results with and without nitrobenzene addition, respectively. Error bars indicate standard deviations of two experiments. 

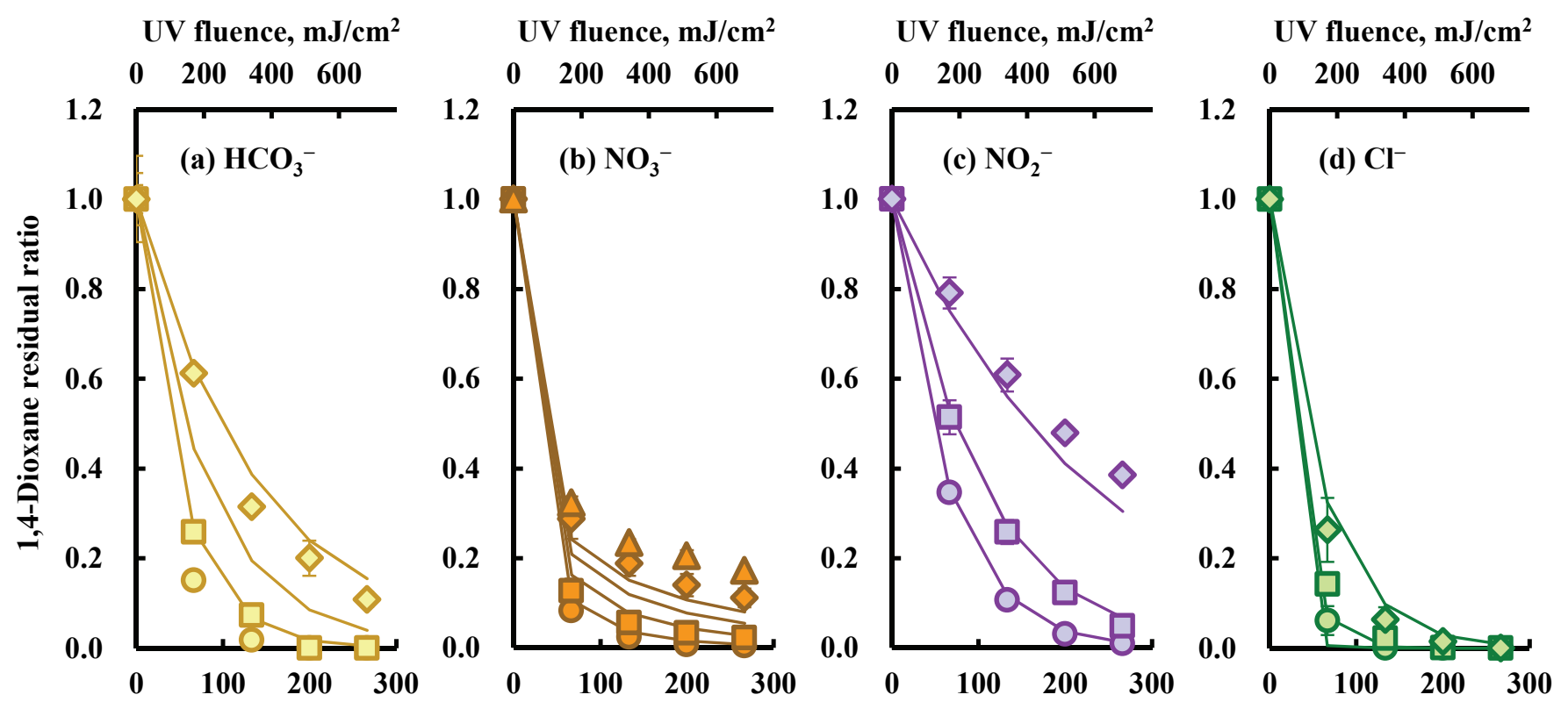

VUV photon dose, $\mu$ moles $/ L \quad$ VUV photon dose, $\mu$ moles $/ L \quad$ VUV photon dose, $\mu$ moles $/ L$

Fig. 5 Comparison between observed (symbols) and calculated (lines) 1,4-dioxoane residual ratios during VUV treatment in

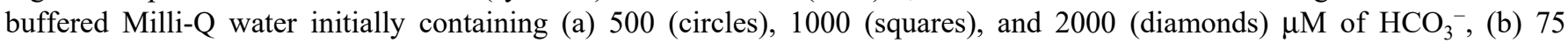

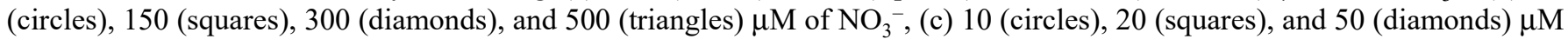
of $\mathrm{NO}_{2}{ }^{-}$, and (d) 1000 (circles), 2000 (squares), and 4000 (diamonds) $\mu \mathrm{M} \mathrm{of} \mathrm{Cl}^{-}$. Error bars indicate standard deviations of at least two experiments. The parameters determined by the fitting were $\Phi_{5}, \Phi_{7}, \Phi_{9}, \varepsilon_{185, \mathrm{NO} 3}, \varepsilon_{185, \mathrm{NO} 2}, k_{41}, k_{51}, k_{71}$, and $k_{75}$. 


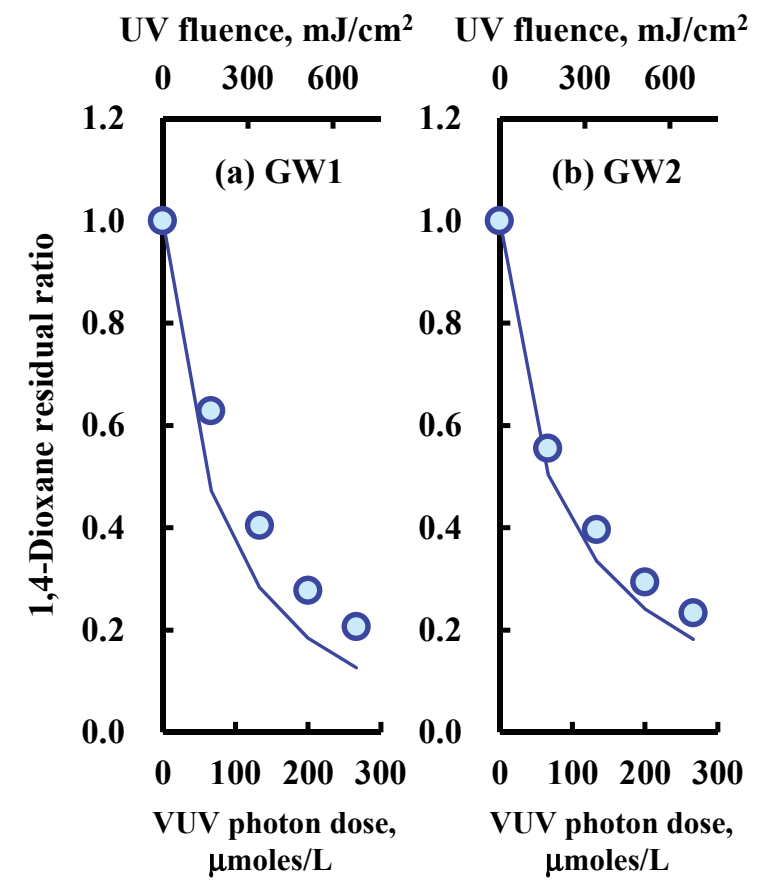

UV fluence, $\mathrm{mJ} / \mathrm{cm}^{2} \quad$ UV fluence, $\mathrm{mJ} / \mathrm{cm}^{2} \quad \mathrm{UV}$ fluence, $\mathrm{mJ} / \mathrm{cm}^{2}$

Fig. 6 Prediction of 1,4-dioxane decomposition in real groundwaters, real river water, and dechlorinated tap water during VUV treatment. Symbols and lines represent observed and predicted values, respectively. Error bars indicate standard deviations of at least two experiments. 


\title{
Supplementary information
}

\section{Prediction of 1,4-dioxane decomposition during VUV treatment by model simulation taking into account effects of coexisting inorganic ions}

\author{
Taku Matsushita ${ }^{a,}{ }^{*}$, Wataru Sugita ${ }^{b}$, Tomoya Ishikawa ${ }^{b}$, Gang Shi ${ }^{b}$, Shota Nishizawa ${ }^{b}$, \\ Yoshihiko Matsui ${ }^{a}$, and Nobutaka Shirasaki ${ }^{a}$ \\ ${ }^{a}$ Faculty of Engineering, Hokkaido University, N13W8, Sapporo 060-8628, Japan \\ ${ }^{b}$ Graduate School of Engineering, Hokkaido University, N13W8, Sapporo 060-8628, Japan \\ *Corresponding author: taku-m@eng.hokudai.ac.jp, +81-11-706-7279
}

$$
\begin{aligned}
& \text { Reactions involved in the model } \\
& \mathrm{H}_{2} \mathrm{O}+h v_{185} \rightarrow \mathrm{HO} \cdot+\mathrm{H} \cdot \\
& \Phi_{1}=0.33 \text { (Imoberdorf and Mohseni 2012) } \\
& \varepsilon_{185, \mathrm{H}_{2} \mathrm{O}}=1.8 \mathrm{~cm}^{-1} \text { (Weeks et al. 1963) } \\
& \mathrm{H}_{2} \mathrm{O}+h v_{185} \rightarrow \mathrm{H}^{+}+\mathrm{e}_{a q}^{-}+\mathrm{HO} \cdot \quad \Phi_{2}=0.045 \text { (Imoberdorf and Mohseni 2012) } \\
& \mathrm{H}_{2} \mathrm{O}_{2}+h v_{185} \rightarrow 2 \mathrm{HO} \cdot \Phi_{3}=0.5 \text { (Imoberdorf and Mohseni 2012) } \\
& \varepsilon_{185, \mathrm{H}_{2} \mathrm{O}_{2}}=2.89 \times 10^{2} \mathrm{M}^{-1} \mathrm{~cm}^{-1} \text { (Imoberdorf and Mohseni 2012) } \\
& \mathrm{H}_{2} \mathrm{O}_{2}+h v_{254} \rightarrow 2 \mathrm{HO} \cdot \Phi_{4}=0.5 \text { (Imoberdorf and Mohseni 2012) } \\
& \varepsilon_{254, \mathrm{H}_{2} \mathrm{O}_{2}}=1.84 \times 10^{1} \mathrm{M}^{-1} \mathrm{~cm}^{-1} \text { (Imoberdorf and Mohseni 2012) } \\
& \mathrm{NO}_{3}^{-}+h v_{185} \rightarrow \mathrm{NO}_{2} \cdot+\mathrm{O}^{\cdot^{-}} \quad \Phi_{5}=0.23 \text { (present study) } \\
& \varepsilon_{185, \mathrm{NO}_{3}}=1.1 \times 10^{4} \mathrm{M}^{-1} \mathrm{~cm}^{-1} \text { (present study) } \\
& \mathrm{NO}_{3}^{-}+h v_{254} \rightarrow \mathrm{NO}_{2} \cdot+\mathrm{O}^{-} \quad \Phi_{6}=0.09 \text { (Mack and Bolton 1999) } \\
& \varepsilon_{254, \mathrm{NO}_{3}}=3.98 \mathrm{M}^{-1} \mathrm{~cm}^{-1} \text { (Bayliss and Bucat 1975) } \\
& \mathrm{NO}_{3}^{-}+h v_{185} \rightarrow \mathrm{NO}_{2}^{-}+\mathrm{O}\left({ }^{3} \mathrm{P}\right) \\
& \Phi_{7}=0.079 \text { (present study) } \\
& \mathrm{NO}_{3}^{-}+h v_{254} \rightarrow \mathrm{NO}_{2}^{-}+\mathrm{O}\left({ }^{3} \mathrm{P}\right) \\
& \Phi_{8}=0.001 \text { (Mack and Bolton 1999) } \\
& \mathrm{NO}_{2}^{-}+h v_{185} \rightarrow \mathrm{NO} \cdot+\mathrm{O}^{--} \\
& \Phi_{9}=0.14 \text { (present study) } \\
& \varepsilon_{185, \mathrm{NO}_{2}}=2.4 \times 10^{4} \mathrm{M}^{-1} \mathrm{~cm}^{-1} \text { (present study) } \\
& \mathrm{NO}_{2}^{-}+h v_{254} \rightarrow \mathrm{NO} \cdot+\mathrm{O}^{--} \\
& \Phi_{10}=0.046 \text { (Mack and Bolton 1999) } \\
& \varepsilon_{254, \mathrm{NO}_{2}}=1.28 \times 10^{1} \mathrm{M}^{-1} \mathrm{~cm}^{-1} \text { (Bayliss and Bucat 1975) }
\end{aligned}
$$




$$
\begin{aligned}
& \mathrm{HO}_{2} \cdot+\mathrm{O}_{2} \cdot \cdot^{-} \rightarrow \mathrm{O}_{2}+\mathrm{HO}_{2}^{-} \quad k_{23}=9.7 \times 10^{7} \mathrm{M}^{-1} \mathrm{~s}^{-1} \text { (Imoberdorf and Mohseni 2012) (S23) } \\
& \mathrm{e}_{a q}^{-}+\mathrm{HO} \cdot \rightarrow \mathrm{HO}^{-} \quad k_{24}=3.0 \times 10^{10} \mathrm{M}^{-1} \mathrm{~s}^{-1} \text { (Imoberdorf and Mohseni 2012) (S24) } \\
& 2 \mathrm{O}_{2} \cdot{ }^{-}+2 \mathrm{H}_{2} \mathrm{O} \rightarrow \mathrm{O}_{2}+\mathrm{H}_{2} \mathrm{O}_{2}+2 \mathrm{HO}^{-} k_{25}=3.0 \times 10^{-1} \mathrm{~s}^{-1} \text { (Imoberdorf and Mohseni 2012) (S25) } \\
& \mathrm{e}_{a q}^{-}+\mathrm{H} \cdot+\mathrm{H}_{2} \mathrm{O} \rightarrow \mathrm{H}_{2}+\mathrm{HO}^{-} \quad k_{26}=2.5 \times 10^{10} \mathrm{M}^{-1} \mathrm{~s}^{-1} \text { (Imoberdorf and Mohseni 2012) (S26) } \\
& \mathrm{HO} \cdot+\mathrm{HO}_{2}^{-} \rightarrow \mathrm{HO}_{2} \cdot+\mathrm{HO}^{-} \quad k_{27}=7.5 \times 10^{9} \mathrm{M}^{-1} \mathrm{~s}^{-1} \text { (Imoberdorf and Mohseni 2012) (S27) } \\
& \mathrm{HO} \cdot+\mathrm{HO}^{-} \rightarrow \mathrm{O}^{--}+\mathrm{H}_{2} \mathrm{O} \quad k_{28}=3.9 \times 10^{8} \mathrm{M}^{-1} \mathrm{~s}^{-1} \text { (Imoberdorf and Mohseni 2012) (S28) } \\
& \mathrm{H} \cdot+\mathrm{HO}^{-} \rightarrow \mathrm{e}_{a q}^{-}+\mathrm{H}_{2} \mathrm{O} \quad k_{29}=3.6 \times 10^{8} \mathrm{M}^{-1} \mathrm{~s}^{-1} \text { (Imoberdorf and Mohseni 2012) (S29) } \\
& \mathrm{H}_{2} \mathrm{O}_{2}+\mathrm{e}_{a q}^{-} \rightarrow \mathrm{HO} \cdot+\mathrm{HO}^{-} \quad k_{30}=1.1 \times 10^{10} \mathrm{M}^{-1} \mathrm{~s}^{-1} \text { (Imoberdorf and Mohseni 2012) (S30) } \\
& \mathrm{e}_{a q}^{-}+\mathrm{H}^{+} \rightarrow \mathrm{H} \cdot \\
& \mathrm{e}_{a q}^{-}+\mathrm{H}_{2} \mathrm{O} \rightarrow \mathrm{H} \cdot+\mathrm{HO}^{-} \\
& \mathrm{H} \cdot+\mathrm{HO}_{2} \cdot \rightarrow \mathrm{H}_{2} \mathrm{O}_{2} \quad k_{33}=1.0 \times 10^{10} \mathrm{M}^{-1} \mathrm{~s}^{-1} \text { (Imoberdorf and Mohseni 2012) } \\
& \mathrm{H}_{2} \mathrm{O}_{2}+\mathrm{H} \cdot \rightarrow \mathrm{HO} \cdot+\mathrm{H}_{2} \mathrm{O} \quad k_{34}=9.0 \times 10^{7} \mathrm{M}^{-1} \mathrm{~s}^{-1} \text { (Imoberdorf and Mohseni 2012) } \\
& \mathrm{e}_{a q}^{-}+\mathrm{HO}_{2}^{-}+\mathrm{H}_{2} \mathrm{O} \rightarrow \mathrm{HO} \cdot+2 \mathrm{HO}^{-} k_{35}=3.5 \times 10^{9} \mathrm{M}^{-1} \mathrm{~s}^{-1} \text { (Imoberdorf and Mohseni 2012) } \\
& \mathrm{H} \cdot+\mathrm{O}_{2} \cdot-\mathrm{HO}_{2}^{-} \quad k_{36}=2.0 \times 10^{10} \mathrm{M}^{-1} \mathrm{~s}^{-1} \text { (Imoberdorf and Mohseni 2012) } \\
& \mathrm{O}^{\cdot-}+\mathrm{H}_{2} \mathrm{O} \rightarrow \mathrm{HO} \cdot+\mathrm{HO}^{-} \quad k_{37}=1.7 \times 10^{6} \mathrm{~s}^{-1} \text { (Mack and Bolton 1999) } \\
& \mathrm{HO}_{2} \cdot+\mathrm{O}_{2} \cdot+\mathrm{H}_{2} \mathrm{O} \rightarrow \mathrm{H}_{2} \mathrm{O}_{2}+\mathrm{O}_{2}+\mathrm{HO}^{-} k_{38}=9.7 \times 10^{7} \mathrm{M}^{-1} \mathrm{~s}^{-1} \text { (Liao and Gurol 1995) } \\
& \mathrm{H}_{2} \mathrm{O} \rightarrow \mathrm{H}^{+}+\mathrm{HO}^{-} \\
& k_{39}=2.5 \times 10^{-5} \mathrm{~s}^{-1} \text { (Eigen and De Maeyer 1958) } \\
& k_{40}=1.4 \times 10^{11} \mathrm{M}^{-1} \mathrm{~s}^{-1} \text { (Eigen and De Maeyer 1958) } \\
& k_{41}=2.8 \times 10^{9} \mathrm{M}^{-1} \mathrm{~s}^{-1} \text { (Bagheri and Mohseni 2017) } \\
& 3.1 \times 10^{9} \mathrm{M}^{-1} \mathrm{~s}^{-1} \text { (Patton et al. 2017) } \\
& 6.5 \times 10^{8} \mathrm{M}^{-1} \mathrm{~s}^{-1} \text { (present study) } \\
& k_{42}=3.9 \times 10^{8} \mathrm{M}^{-1} \mathrm{~s}^{-1} \text { (Crittenden et al. 1999) }(\mathrm{S} 42) \\
& k_{43}=8.5 \times 10^{6} \mathrm{M}^{-1} \mathrm{~s}^{-1} \text { (Crittenden et al. 1999) (S43) } \\
& k_{44}=4.3 \times 10^{5} \mathrm{M}^{-1} \mathrm{~s}^{-1} \text { (Crittenden et al. 1999) (S44) } \\
& k_{45}=3.0 \times 10^{7} \mathrm{M}^{-1} \mathrm{~s}^{-1} \text { (Crittenden et al. 1999) (S45) } \\
& \mathrm{CO}_{3} .^{-}+\mathrm{HO}_{2}^{-} \rightarrow \mathrm{CO}_{3}^{2-}+\mathrm{HO}_{2} \text {. } \\
& \mathrm{H}_{2} \mathrm{CO}_{3} \rightarrow \mathrm{HCO}_{3}^{-}+\mathrm{H}^{+} \\
& \mathrm{HCO}_{3}^{-}+\mathrm{H}^{+} \rightarrow \mathrm{H}_{2} \mathrm{CO}_{3} \\
& \mathrm{HCO}_{3}^{-} \rightarrow \mathrm{CO}_{3}^{2-}+\mathrm{H}^{+} \\
& \mathrm{CO}_{3}^{2-}+\mathrm{H}^{+} \rightarrow \mathrm{HCO}_{3}^{-} \\
& \mathrm{Cl}^{-}+\mathrm{HO} \cdot \rightarrow \mathrm{ClHO} \cdot- \\
& \mathrm{ClHO} \cdot{ }^{-} \rightarrow \mathrm{Cl}^{-}+\mathrm{HO} \text {. } \\
& k_{46}=5.0 \times 10^{3} \mathrm{~s}^{-1} \text { (Matthew and Anastasio 2006) (S46) } \\
& k_{47}=1.0 \times 10^{10} \mathrm{M}^{-1} \mathrm{~s}^{-1} \text { (Matthew and Anastasio 2006) (S47) } \\
& k_{48}=2.5 \mathrm{~s}^{-1} \text { (Matthew and Anastasio 2006) (S48) } \\
& k_{49}=5.0 \times 10^{10} \mathrm{M}^{-1} \mathrm{~s}^{-1} \text { (Matthew and Anastasio 2006) }(\mathrm{S} 49) \\
& k_{50}=4.3 \times 10^{9} \mathrm{M}^{-1} \mathrm{~s}^{-1} \text { (Matthew and Anastasio 2006) } \\
& k_{51}=6.1 \times 10^{9} \mathrm{~s}^{-1} \text { (Matthew and Anastasio 2006) } \\
& 1.0 \times 10^{6} \mathrm{~s}^{-1} \text { (present study) (S51) } \\
& \mathrm{ClHO} \cdot^{-}+\mathrm{Cl}^{-} \rightarrow \mathrm{Cl}_{2} \cdot^{-}+\mathrm{HO}^{-} \quad k_{52}=1.0 \times 10^{5} \mathrm{M}^{-1} \mathrm{~s}^{-1} \text { (Matthew and Anastasio 2006) } \\
& k_{53}=2.1 \times 10^{10} \mathrm{M}^{-1} \mathrm{~s}^{-1} \text { (Matthew and Anastasio 2006) } \\
& k_{54}=6.5 \times 10^{9} \mathrm{M}^{-1} \mathrm{~s}^{-1} \text { (Matthew and Anastasio 2006) } \\
& k_{55}=1.1 \times 10^{5} \mathrm{~s}^{-1} \text { (Matthew and Anastasio 2006) (S55) } \\
& \mathrm{Cl}_{2} \cdot-\rightarrow \mathrm{Cl}^{-}+\mathrm{Cl} \text {. } \\
& k_{56}=3.0 \times 10^{9} \mathrm{M}^{-1} \mathrm{~s}^{-1} \text { (Matthew and Anastasio 2006) (S56) } \\
& k_{57}=1.0 \times 10^{9} \mathrm{M}^{-1} \mathrm{~s}^{-1} \text { (Matthew and Anastasio 2006) }
\end{aligned}
$$


$\mathrm{Cl}_{2} \cdot{ }^{-}+\mathrm{H}_{2} \mathrm{O}_{2} \rightarrow 2 \mathrm{Cl}^{-}+\mathrm{HO}_{2} \cdot+\mathrm{H}^{+} k_{58}=1.4 \times 10^{5} \mathrm{M}^{-1} \mathrm{~s}^{-1}$ (Matthew and Anastasio 2006) (S58)

$\mathrm{Cl} \cdot+\mathrm{CO}_{3}^{2-} \longrightarrow \mathrm{Cl}^{-}+\mathrm{CO}_{3} \cdot{ }^{-} \quad k_{59}=5.0 \times 10^{8} \mathrm{M}^{-1} \mathrm{~s}^{-1}$ (Matthew and Anastasio 2006) (S59)

$\mathrm{Cl} \cdot+\mathrm{HCO}_{3}^{-} \rightarrow \mathrm{Cl}^{-}+\mathrm{CO}_{3} \cdot{ }^{-}+\mathrm{H}^{+} \quad k_{60}=2.2 \times 10^{8} \mathrm{M}^{-1} \mathrm{~s}^{-1}$ (Matthew and Anastasio 2006) (S60)

$\mathrm{Cl}_{2} \cdot^{-}+\mathrm{CO}_{3}^{2-} \rightarrow 2 \mathrm{Cl}^{-}+\mathrm{CO}_{3} .^{-} \quad k_{61}=8.0 \times 10^{7} \mathrm{M}^{-1} \mathrm{~s}^{-1}$ (Matthew and Anastasio 2006) (S61)

$\mathrm{Cl}_{2} \cdot^{-}+\mathrm{HCO}_{3}^{-} \rightarrow 2 \mathrm{Cl}^{-}+\mathrm{CO}_{3} \cdot{ }^{-}+\mathrm{H}^{+} k_{62}=1.6 \times 10^{8} \mathrm{M}^{-1} \mathrm{~s}^{-1}$ (Matthew and Anastasio 2006)

$$
\begin{aligned}
& \mathrm{NO}_{2} \cdot+\mathrm{HO} \cdot \rightarrow \mathrm{HOONO} \quad k_{63}=1.3 \times 10^{9} \mathrm{M}^{-1} \mathrm{~s}^{-1} \text { (Mack and Bolton 1999) (S63) } \\
& \mathrm{ONOO}^{-}+\mathrm{H}^{+} \rightarrow \text { HOONO } \quad k_{64}=1.0 \times 10^{10} \mathrm{M}^{-1} \mathrm{~s}^{-1} \text { (Mack and Bolton 1999) (S64) } \\
& \mathrm{HOONO} \rightarrow \mathrm{ONOO}^{-}+\mathrm{H}^{+} \quad k_{65}=3.2 \times 10^{16} \mathrm{~s}^{-1} \text { (Mack and Bolton 1999) (S65) } \\
& \mathrm{ONOO}^{-}+\mathrm{HO} \cdot \rightarrow \mathrm{ONOO} \cdot+\mathrm{HO}^{-} \quad k_{66}=5.0 \times 10^{9} \mathrm{M}^{-1} \mathrm{~s}^{-1} \text { (Mack and Bolton 1999) (S66) } \\
& \mathrm{ONOO} \cdot \mathrm{NO} \cdot+\mathrm{O}_{2} \quad k_{67}=1.0 \times 10^{10} \mathrm{~s}^{-1} \text { (Mack and Bolton 1999) (S67) } \\
& \mathrm{NO}_{2} \cdot+\mathrm{ONOO} \cdot+\mathrm{H}_{2} \mathrm{O} \rightarrow 2 \mathrm{NO}_{3}^{-}+2 \mathrm{H}^{+} k_{68}=1.0 \times 10^{10} \mathrm{M}^{-1} \mathrm{~s}^{-1} \text { (Mack and Bolton 1999) (S68) } \\
& \mathrm{NO}_{2} \cdot+\mathrm{H} \cdot \rightarrow \mathrm{HNO}_{2} \quad k_{69}=6.0 \times 10^{8} \mathrm{M}^{-1} \mathrm{~s}^{-1} \text { (Gonzalez and Braun 1995) (S69) } \\
& \mathrm{NO}_{3}^{-}+\mathrm{HO} \cdot \rightarrow \mathrm{NO}_{3} \cdot+\mathrm{HO}^{-} \quad k_{70}=1.0 \times 10^{5} \mathrm{M}^{-1} \mathrm{~s}^{-1} \text { (Gonzalez and Braun 1995) (S70) } \\
& \mathrm{NO}_{2}^{-}+\mathrm{HO} \cdot \rightarrow \mathrm{NO}_{2} \cdot+\mathrm{HO}^{-} \quad k_{71}=1.0 \times 10^{10} \mathrm{M}^{-1} \mathrm{~s}^{-1} \text { (Mack and Bolton 1999) } \\
& \mathrm{NO}_{3}^{-}+\mathrm{O}\left({ }^{3} \mathrm{P}\right) \rightarrow \mathrm{NO}_{2}^{-}+\mathrm{O}_{2} \quad k_{72}=3.0 \times 10^{8} \mathrm{M}^{-1} \mathrm{~s}^{-1} \text { (Mack and Bolton 1999) } \\
& \mathrm{NO}_{2}^{-}+\mathrm{O}\left({ }^{3} \mathrm{P}\right) \rightarrow \mathrm{NO}_{3}^{-} \\
& 2 \mathrm{NO}_{2} \cdot \rightarrow \mathrm{N}_{2} \mathrm{O}_{4} \\
& \mathrm{~N}_{2} \mathrm{O}_{4} \rightarrow 2 \mathrm{NO}_{2} \text {. } \\
& \mathrm{N}_{2} \mathrm{O}_{4}+\mathrm{H}_{2} \mathrm{O} \rightarrow \mathrm{NO}_{3}^{-}+\mathrm{NO}_{2}^{-}+2 \mathrm{H}^{+} \\
& \mathrm{NO}_{2} \cdot+\mathrm{O}_{2} \cdot{ }^{-} \rightarrow \mathrm{O}_{2}+\mathrm{NO}_{2}^{-} \\
& 2 \mathrm{NO} \cdot+\mathrm{O}_{2} \rightarrow \mathrm{N}_{2} \mathrm{O}_{4} \\
& \mathrm{NO} \cdot+\mathrm{HO} \cdot \rightarrow \mathrm{HNO}_{2} \\
& \mathrm{H}^{+}+\mathrm{NO}_{2}^{-} \rightarrow \mathrm{HNO}_{2} \\
& \mathrm{HNO}_{2} \rightarrow \mathrm{H}^{+}+\mathrm{NO}_{2}^{-} \\
& \mathrm{NO}_{2} \cdot+\mathrm{e}_{a q}^{-} \rightarrow \mathrm{NO}_{2}^{-} \\
& \mathrm{NO} \cdot+\mathrm{NO}_{2} \cdot \rightarrow \mathrm{N}_{2} \mathrm{O}_{3} \\
& \mathrm{~N}_{2} \mathrm{O}_{3}+\mathrm{H}_{2} \mathrm{O} \rightarrow 2 \mathrm{NO}_{2}^{-}+2 \mathrm{H}^{+} \\
& 6.7 \times 10^{8} \mathrm{M}^{-1} \mathrm{~s}^{-1} \text { (present study) (S71) } \\
& k_{73}=3.0 \times 10^{9} \mathrm{M}^{-1} \mathrm{~s}^{-1} \text { (Mack and Bolton 1999) }(\mathrm{S} 73) \\
& k_{74}=4.5 \times 10^{8} \mathrm{~s}^{-1} \text { (Mack and Bolton 1999) (S74) } \\
& k_{75}=6.9 \times 10^{3} \mathrm{~s}^{-1} \text { (Gonzalez and Braun 1995) } \\
& 1.3 \times 10^{7} \mathrm{~s}^{-1} \text { (present study) (S75) } \\
& k_{76}=1.0 \times 10^{3} \mathrm{~s}^{-1} \text { (Mack and Bolton 1999) (S76) } \\
& k_{77}=1.0 \times 10^{8} \mathrm{M}^{-1} \mathrm{~s}^{-1} \text { (Mack and Bolton 1999) }(\mathrm{S} 77) \\
& k_{78}=1.0 \times 10^{5} \mathrm{M}^{-1} \mathrm{~s}^{-1} \text { (Mack and Bolton 1999) (S78) } \\
& k_{79}=1.0 \times 10^{10} \mathrm{M}^{-1} \mathrm{~s}^{-1} \text { (Mack and Bolton 1999) }(\mathrm{S} 79) \\
& k_{80}=1.0 \times 10^{10} \mathrm{M}^{-1} \mathrm{~s}^{-1} \text { (Mack and Bolton 1999) (S80) } \\
& k_{81}=1.6 \times 10^{13} \mathrm{~s}^{-1} \text { (Mack and Bolton 1999) }(\mathrm{S} 81) \\
& k_{82}=4.6 \times 10^{8} \mathrm{M}^{-1} \mathrm{~s}^{-1} \text { (Mack and Bolton 1999) }(\mathrm{S} 82) \\
& k_{83}=1.1 \times 10^{9} \mathrm{M}^{-1} \mathrm{~s}^{-1} \text { (Mack and Bolton 1999) }(\mathrm{S} 83) \\
& k_{84}=5.3 \times 10^{2} \mathrm{~s}^{-1} \text { (Mack and Bolton 1999) } \quad(\mathrm{S} 84)
\end{aligned}
$$




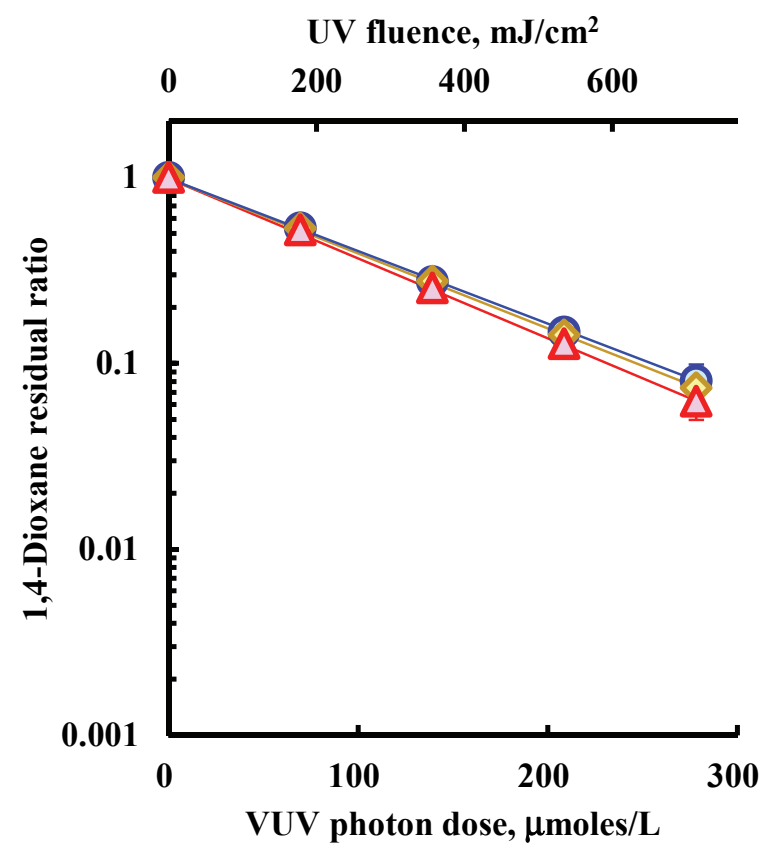

Fig. S1 Comparison of 1,4-dioxane residual ratios among buffered dechlorinated tap waters containing $\mathrm{Na}^{+}$(blue circles), $\mathrm{Ca}^{2+}$ (yellow diamonds), and $\mathrm{Mg}^{2+}$ (red triangles). Error bars indicate standard deviations of at least two experiments.

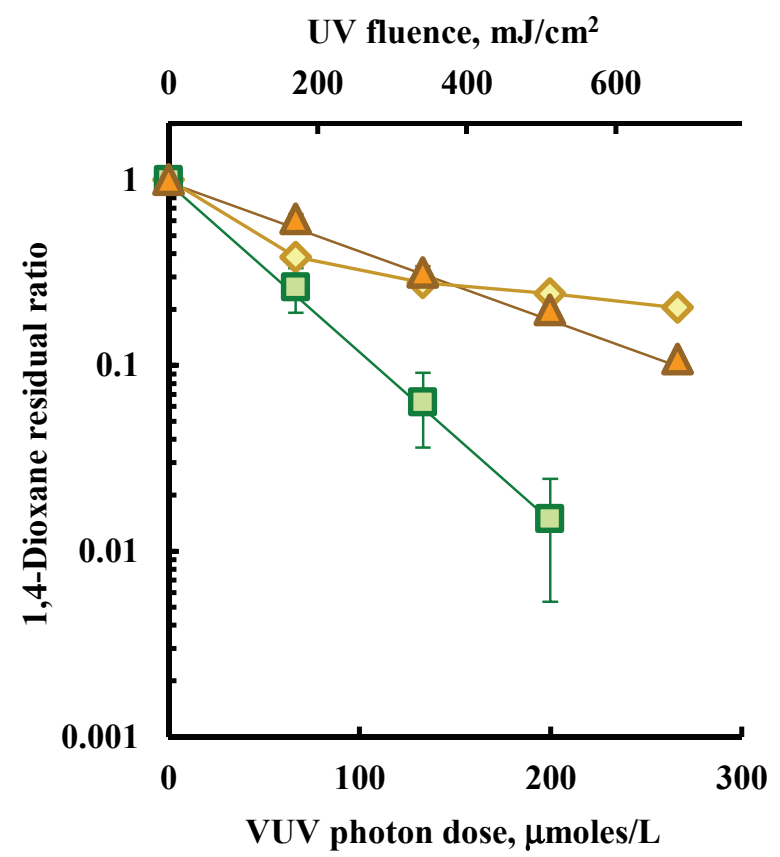

Fig. S3 Comparison in trends of 1,4-dioxane residual ratios among buffered Milli-Q waters with $4000 \mu \mathrm{M}$ of $\mathrm{Cl}^{-}$(green squares), $2000 \mu \mathrm{M}$ of $\mathrm{HCO}_{3}^{-}$ (orange triangles), and $500 \mu \mathrm{M}$ of $\mathrm{NO}_{3}^{-}$(yellow diamonds). Error bars indicate standard deviations of at least three experiments.

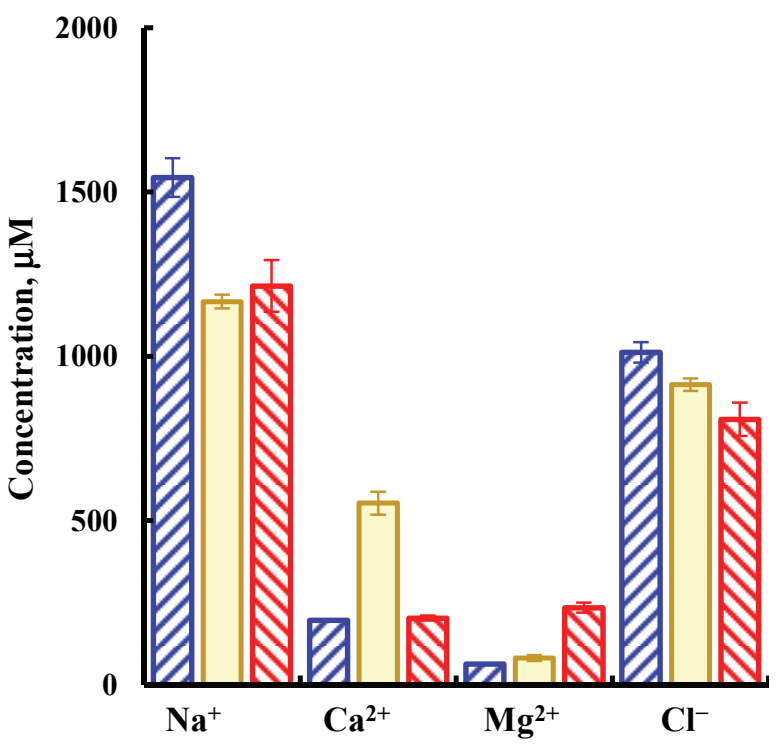

Fig. S2 Ion concentrations in buffered dechlorinated tap waters containing $\mathrm{Na}^{+}$(blue hatched columns), $\mathrm{Ca}^{2+}$ (yellow columns), and $\mathrm{Mg}^{2+}$ (red hatched columns). Error bars indicate standard deviations of at least two experiments.

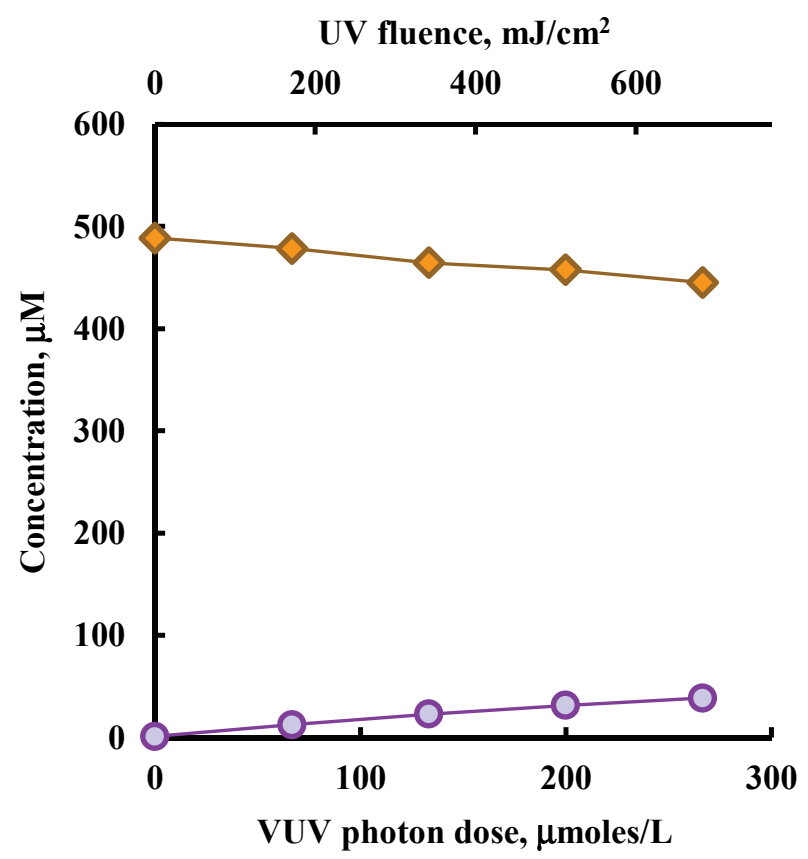

Fig. S4 Changes in concentrations of $\mathrm{NO}_{3}{ }^{-}$(orange diamonds) and $\mathrm{NO}_{2}^{-}$(purple circles) with VUV treatment in buffered Milli-Q water initially containing $500 \mu \mathrm{M}$ of $\mathrm{NO}_{3}^{-}$. Error bars indicate standard deviations of three experiments. 

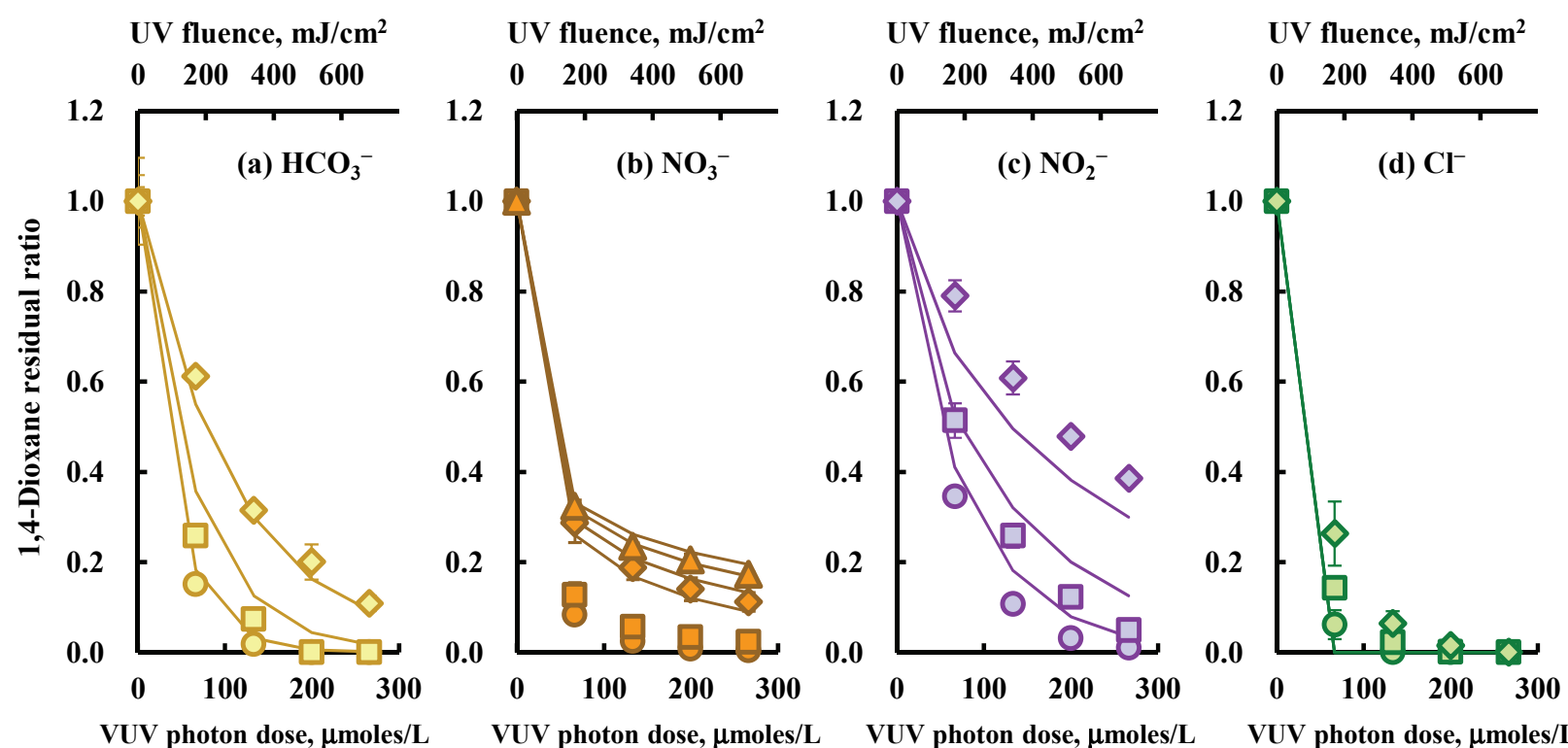

Fig. S5 Comparison between observed (plots) and calculated (lines) 1,4-dioxoane residual ratios during VUV treatment in buffered Milli-Q water initially containing (a) 500 (circles), 1000 (squares), and 2000 (diamonds) $\mu \mathrm{M}$ of $\mathrm{HCO}_{3}^{-}$, (b) 75 (circles), 150 (squares), 300 (diamonds), and 500 (triangles) $\mu \mathrm{M}$ of $\mathrm{NO}_{3}^{-}$, (c) 10 (circles), 20 (squares), and 50 (diamonds) $\mu \mathrm{M}$ of $\mathrm{NO}_{2}{ }^{-}$, and (d) 1000 (circles), 2000 (squares), and 4000 (diamonds) $\mu \mathrm{M}$ of $\mathrm{Cl}^{-}$. Error bars indicate standard deviations of at least two experiments. The parameters determined by the fitting were $\Phi_{5}, \Phi_{7}, \Phi_{9}, \varepsilon_{185, \mathrm{NO} 3}, \varepsilon_{185, \mathrm{NO} 2}$, and $k_{41}$.

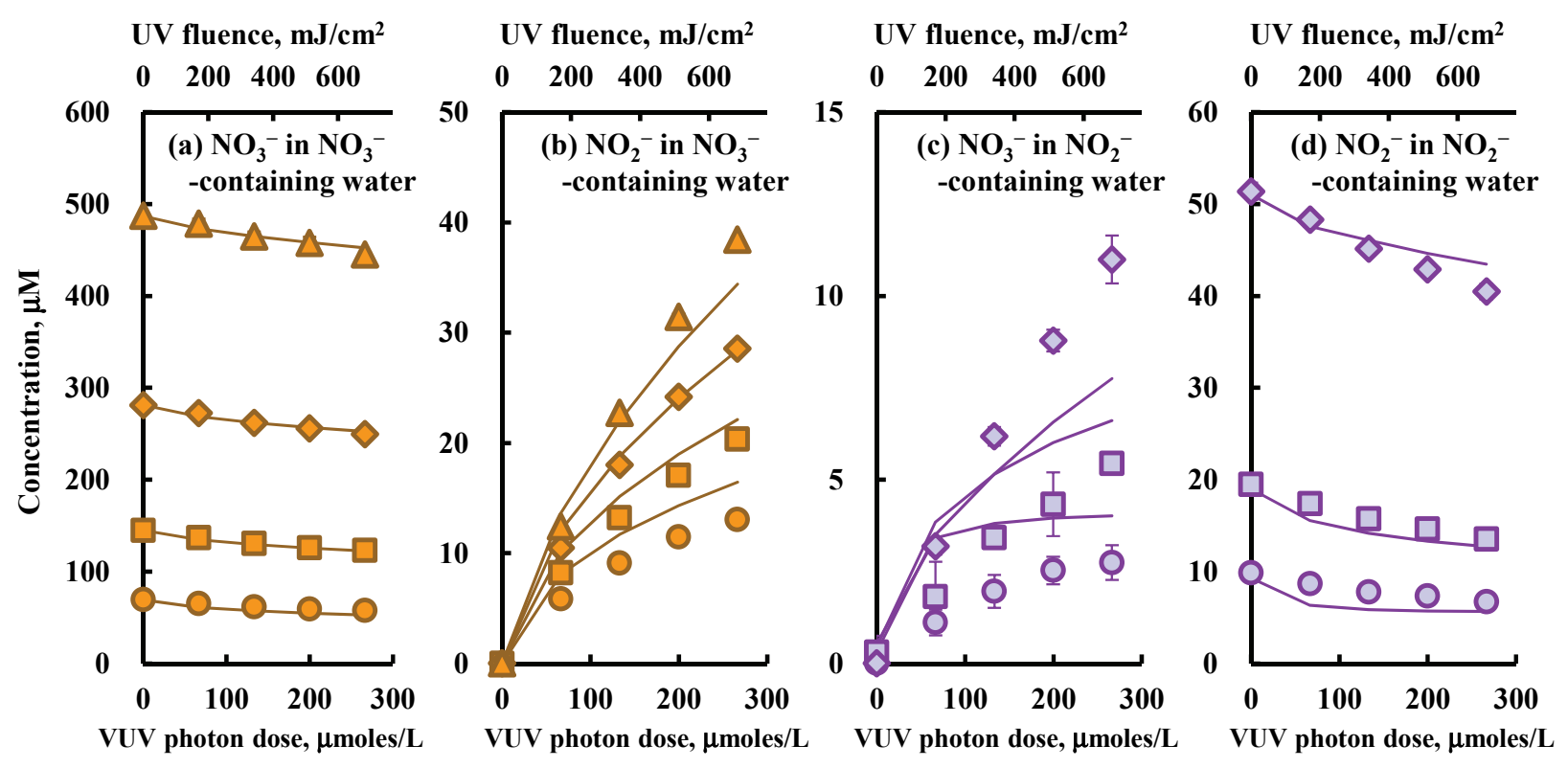

Fig. S6 Comparison between observed (symbols) and calculated (lines) $\mathrm{NO}_{3}{ }^{-} / \mathrm{NO}_{2}{ }^{-}$concentrations during VUV treatment on buffered Milli-Q water. (a) $\mathrm{NO}_{3}{ }^{-}$and (b) $\mathrm{NO}_{2}{ }^{-}$concentrations in buffered Milli-Q waters initially containing (circles) 75, (squares) 150, (diamonds) 300, and (triangles) $500 \mu \mathrm{M}$ of $\mathrm{NO}_{3}^{-}$. (c) $\mathrm{NO}_{3}^{-}$and (d) $\mathrm{NO}_{2}{ }^{-}$concentrations in buffered Milli-Q waters initially containing (circles) 10 , (squares) 20 , and (diamonds) $50 \mu \mathrm{M}$ of $\mathrm{NO}_{2}^{-}$. Error bars indicate standard deviations of at least two experiments. The parameters determined by the fitting were $\Phi_{5}, \Phi_{7}, \Phi_{9}, \varepsilon_{185, \mathrm{NO} 3}, \varepsilon_{185, \mathrm{NO} 2}$, and $k_{41}$. 


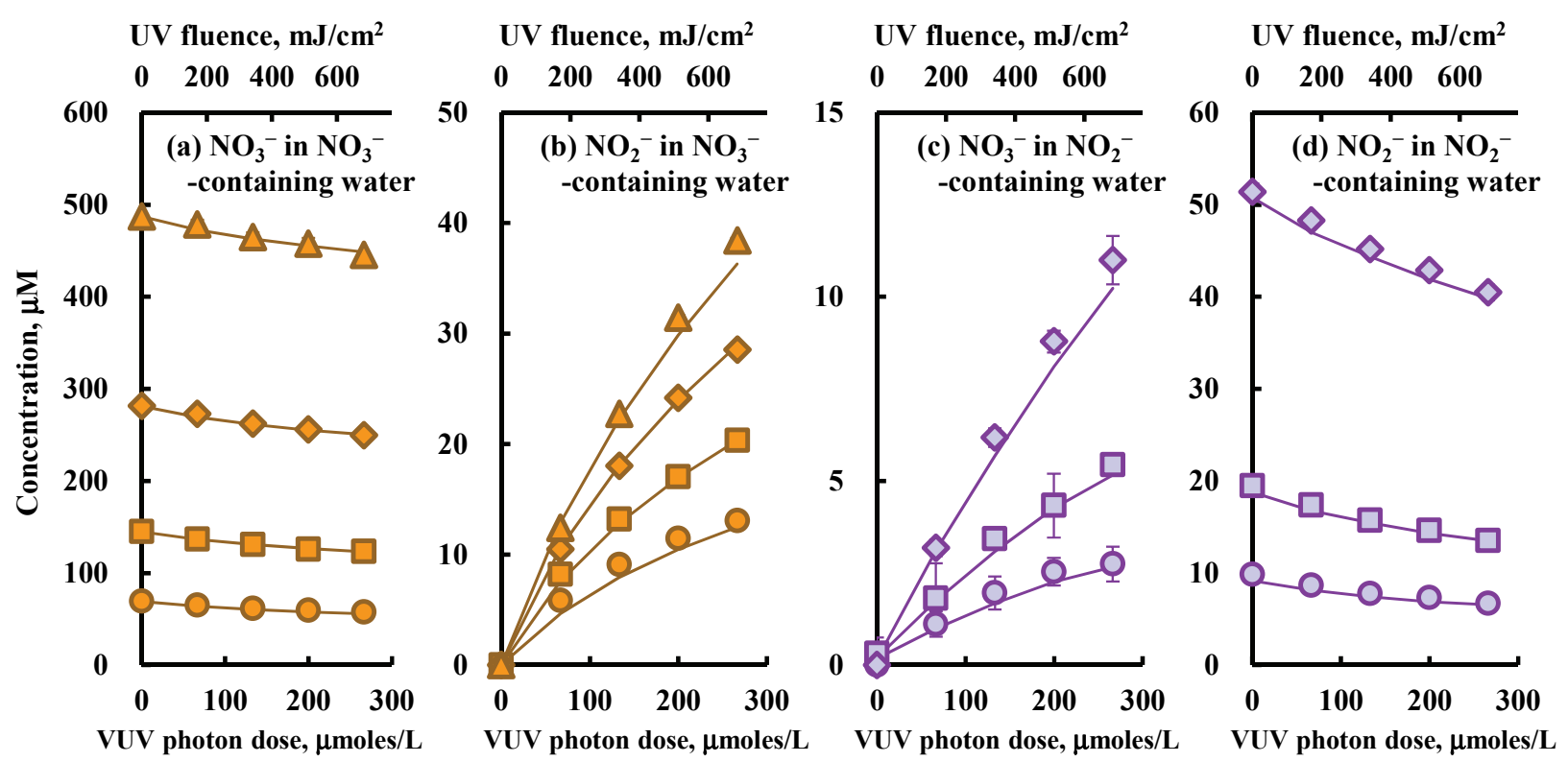

Fig. S7 Comparison between observed (symbols) and calculated (lines) $\mathrm{NO}_{3}{ }^{-} / \mathrm{NO}_{2}{ }^{-}$concentrations during VUV treatment in buffered Milli-Q water. (a) $\mathrm{NO}_{3}{ }^{-}$and (b) $\mathrm{NO}_{2}^{-}$concentrations in buffered Milli-Q waters initially containing (circles) 75, (squares) 150 , (diamonds) 300, and (triangles) $500 \mu \mathrm{M}$ of $\mathrm{NO}_{3}^{-}$. (c) $\mathrm{NO}_{3}^{-}$and (d) $\mathrm{NO}_{2}^{-}$concentrations in buffered Milli-Q waters initially containing (circles) 10 , (squares) 20 , and (diamonds) $50 \mu \mathrm{M}$ of $\mathrm{NO}_{2}^{-}$. Error bars indicate standard deviations of at least two experiments. The parameters determined by the fitting were $\Phi_{5}, \Phi_{7}, \Phi_{9}, \varepsilon_{185, \mathrm{NO} 3}, \varepsilon_{185, \mathrm{NO} 2}, k_{41}, k_{51}, k_{71}$, and $k_{75}$.

\section{References}

Bagheri, M. and Mohseni, M. (2017) Pilot-scale treatment of 1,4-dioxane contaminated waters using $185 \mathrm{~nm}$ radiation: Experimental and CFD modeling. Journal of Water Process Engineering 19, 185-192.

Bayliss, N. and Bucat, R. (1975) The photolysis of aqueous nitrate solutions. Australian Journal of Chemistry 28(9), 1865-1878.

Crittenden, J.C., Hu, S., Hand, D.W. and Green, S.A. (1999) A kinetic model for $\mathrm{H}_{2} \mathrm{O}_{2} / \mathrm{UV}$ process in a completely mixed batch reactor. Water Research 33(10), 2315-2328.

Eigen, M. and De Maeyer, L. (1958) Self-dissociation and protonic charge transport in water and. Proceedings of the Royal Society of London. Series A. Mathematical and Physical Sciences 247(1251), 505-533.

Gonzalez, M.C. and Braun, A.M. (1995) VUV photolysis of aqueous solutions of nitrate and nitrite. Research on Chemical Intermediates 21(8), 837-859.

Imoberdorf, G.E. and Mohseni, M. (2012) Kinetic study and modeling of the vacuum-UV photoinduced degradation of 2,4-D. Chemical Engineering Journal 187, 114-122.

Liao, C.-H. and Gurol, M.D. (1995) Chemical oxidation by photolytic decomposition of hydrogen peroxide. Environmental Science \& Technology 29(12), 3007-3014.

Mack, J. and Bolton, J.R. (1999) Photochemistry of nitrite and nitrate in aqueous solution: a review. Journal of Photochemistry and Photobiology A: Chemistry 128(1), 1-13.

Matthew, B.M. and Anastasio, C. (2006) A chemical probe technique for the determination of reactive halogen species in aqueous solution: Part 1 - bromide solutions. Atmospheric Chemistry and 
Physics 6(9), 2423-2437.

Patton, S., Li, W., Couch, K.D., Mezyk, S.P., Ishida, K.P. and Liu, H. (2017) Impact of the ultraviolet photolysis of monochloramine on 1,4-dioxane removal: new insights into potable water reuse. Environmental Science \& Technology Letters 4(1), 26-30.

Weeks, J.L., Meaburn, G.M.A.C. and Gordon, S. (1963) Absorption coefficients of liquid water and aqueous solutions in the far ultraviolet. Radiation Research 19(3), 559-567. 